\title{
MicroRNA Expression Signatures Determine Prognosis and Survival in Glioblastoma Multiforme—a Systematic Overview
}

\author{
Michael Henriksen • Kasper Bendix Johnsen • \\ Hjalte Holm Andersen • Linda Pilgaard • Meg Duroux
}

Received: 18 December 2013 / Accepted: 25 February 2014 / Published online: 12 March 2014

(C) The Author(s) 2014. This article is published with open access at Springerlink.com

\begin{abstract}
Despite advances in our knowledge about glioblastoma multiforme (GBM) pathology, clinical challenges still lie ahead with respect to treatment in GBM due to high prevalence, poor prognosis, and frequent tumor relapse. The implication of microRNAs (miRNAs) in GBM is a rapidly expanding field of research with the aim to develop more targeted molecular therapies. This review aims to present a comprehensive overview of all the available literature, evaluating miRNA signatures as a function of prognosis and survival in GBM. The results are presented with a focus on studies derived from clinical data in databases and independent tissue cohorts where smaller samples sizes were investigated. Here, miRNA associated to longer survival (protective) and miRNA with shorter survival (risk-associated) have been identified and their signatures based on different prognostic attributes are described. Finally, miRNAs associated with disease progression or survival in several studies are identified and functionally described. These miRNAs may be valuable for future determination of patient prognosis and could possibly serve as targets for miRNA-based therapies, which hold a great potential in the treatment of this severe malignant disease.
\end{abstract}

Keywords MicroRNA · Glioblastoma multiforme · Glioma . Survival $\cdot$ Signature $\cdot$ Prognosis

M. Henriksen · K. B. Johnsen · H. H. Andersen · L. Pilgaard ·

M. Duroux $(\square)$

Laboratory for Cancer Biology, Institute of Health Science and

Technology, Aalborg University, Fredrik Bajers Vej 3B,

9220 Aalborg Ø, Denmark

e-mail: megd@hst.aau.dk

\section{Introduction}

Glioblastoma multiforme (GBM) is a severe type of brain cancer characterized by its large growth potential and very poor clinical outcome. It is one of the most aggressive and incurable types of cancer reflected in a median survival of less than 1 year of all GBM cases and a 5-year survival rate of less than $5 \%[1,2]$. GBM affects $2-3$ per 100,000 persons per year making it a rare type of cancer, but still, it accounts for $16 \%$ of all brain tumors and $54 \%$ of all clinically diagnosed gliomas in the USA [2]. The clinical presentation of GBM depends on the location of the tumors and generally involves focal neurological deficits, headaches, and seizures. Tumors are most commonly found in the frontal lobes of the supratentorial compartments; however, they are not restricted to these areas, as illustrated by GBM tumors found in other parts of the central nervous system (CNS), such as the spinal cord and brainstem [3].

GBM can be subdivided into de novo-occurring tumors, termed primary GBM, or tumors developed from lower-grade astrocytomas, termed secondary GBM. The most prominent occurring subtype of GBM is the primary tumors. These tumors are often characterized by amplification or overexpression of the epidermal growth factor receptor (EGFR) (40$60 \%$ of all primary GBM tumors) combined with genetic alterations in the EGFR gene, which results in mutated forms of this receptor [1]. This is opposed to secondary GBM, which is characterized by progressive addition of mutations in $\mathrm{p} 53$, platelet-derived growth factor receptor, and the retinoblastoma gene [4-6]. Nevertheless, this distinctive division of mutations into the different GBM subtypes is not definitive [3].

Determination of disease prognosis is most often based on histological classification combined with information on patient age and tumor size and location. These factors have all 
been defined as indicators of patient survival and treatment outcome, but due to the sustained poor overall survival of GBM patients, new arrays of prognostic indicators have been requested to aid in the clinical decision making [1]. In recent years, several molecular biomarkers have been characterized including chromosomal aberrations, methylation status of the methyl guanine methyl transferase (MGMT) promoter, mutations in important genes (isocitrate dehydrogenase 1 (IDH1), EGFR, and p53), and dysregulation of microRNAs [7]. Loss of heterozygosity in chromosomes $9 p$ and $10 q$ is associated with decreased survival, while co-deletion of $1 p$ and $19 q$ correlates with better treatment response and longer survival [7]. Hypermethylation of the MGMT promoter leads to lower expression levels of MGMT, which sensitizes GBM tumors to chemotherapeutic treatment and thus is associated with a significantly better patient outcome $[8,9]$. Improvement of the disease condition is also observed in patients with mutation in the IDH1 gene, which is most often found in secondary GBM. Furthermore, the expressional profile of specific microRNA signatures also correlates with overall survival, time to progression, and treatment success [10-12].

\section{The Fundamentals of MicroRNAs}

MicroRNA (miRNA) is a class of non-coding single-stranded RNA comprised of approximately 22 nucleotides with the ability to negatively regulate gene expression posttranscriptionally $[13,14]$. miRNAs bind to the 3 ' untranslated regions (UTRs), and sometimes 5'UTRs, of their messenger RNA (mRNA) targets, to which they exhibit imperfect complementarity, hence, enabling one miRNA to inhibit translation of multiple genes $[15,16]$. The first miRNA was discovered in 1993 in Caenorhabditis elegans and denoted lin-4 [17]. Later, upon the discovery of let-7, found to be conserved in several species, miRNA regulation was recognized as an omnipresent phenomenon in eukaryotic organisms $[18,19]$. miRNAs are acknowledged as crucial micromodulators of normal cellular homeostasis, and accordingly, dysregulation of miRNAs have been associated with a wide range of pathological conditions, such as cancer [20], cardiovascular disease [21, 22], and autoimmune [23] and neurodegenerative disorders [24]. Expression of miRNAs in pathological specimens or biofluids, compared to non-pathologic samples, is subject to great scientific efforts [25]. This poses interesting perspectives in terms of novel diagnostic and prognostic approaches and is inherently the initial step in uncovering the role of individual miRNAs in the context of different diseases, eventually paving the way for novel miRNA-based therapies.

\section{MicroRNA Biogenesis}

To understand the context of miRNA as a potential prognostic tool in patients with GBM, the essential steps in the biogenesis of miRNAs and the modes by which they exert their repression on downstream targets are summarized (see Fig. 1).

The linear biogenesis of miRNA begins with the transcription of miRNA genes by RNA polymerase II/III, giving rise to

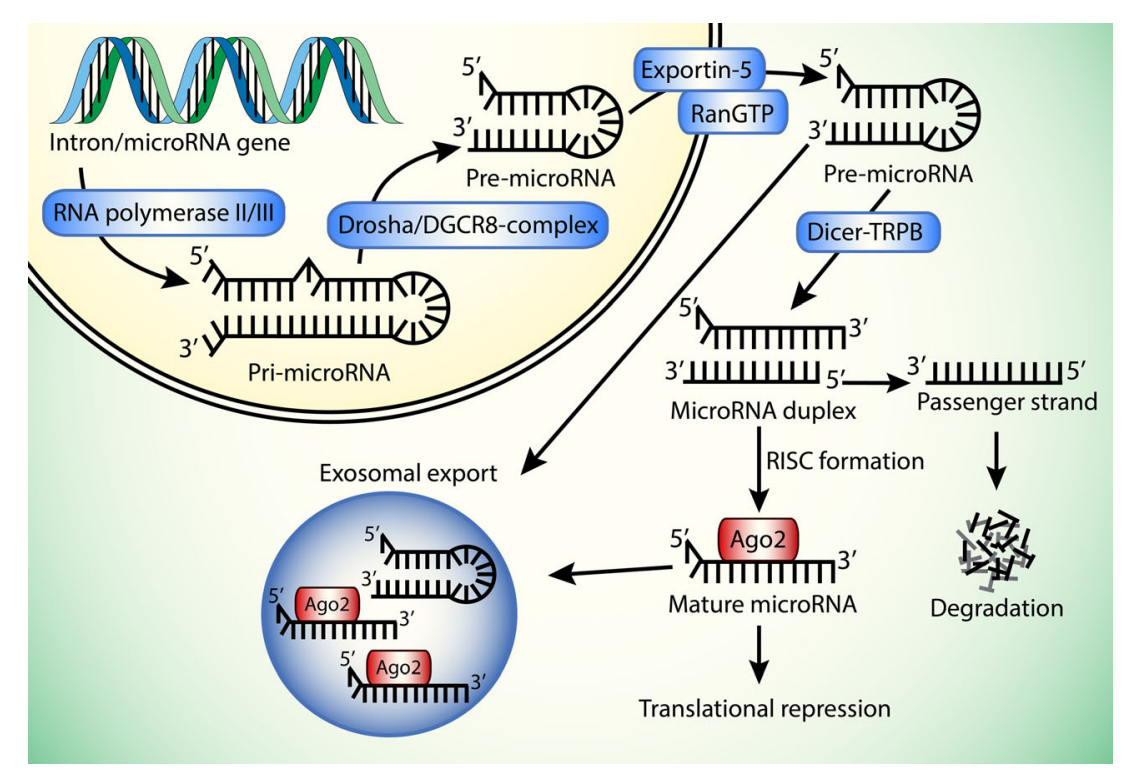

Fig. 1 The biogenesis of miRNA requires RNA polymerase II/III for the transcription of pri-miRNA. The pri-miRNA product is then cleaved by the Drosha-DGCR8 complex into pre-miRNA. The pre-miRNA is exported to the cytoplasm by Exportin-5 in the presence of Ran-GTP co-factor. Once in the cytoplasm, the pre-miRNA is cleaved by the DicerTRBP complex into a miRNA duplex, which is unwound into two products: a guide strand bound to Ago2, which is incorporated into the
RISC, and a passenger strand, which is degraded. Finally, the miRNA binds to its target mRNAs resulting in mRNA target cleavage, translational repression, or mRNA decay. A more novel fate of the miRNAs is the selective secretion via microvesicles or exosomes. Ran=Ras-related nuclear protein; GTP=guanosine-5'-triphosphate; TRBP=TAR $(\mathrm{HIV}-1)$ RNA binding protein; Ago $2=$ Argonaute protein $2 ; \mathrm{RISC}=\mathrm{RNA}$-induced silencing complex 
a primary transcript called pri-miRNA, which is subsequently polyadenylated and capped. The transcript then folds into a hairpin-loop structure via intrastrand base-pairing [26]. This structure is cleaved by the Drosha/DGCR8 complex to become pre-miRNA and transported out of the nucleus by Exportin-5 in a Ran-GTP-dependent process [27]. In the cell cytoplasm, the RNAse-III enzyme known as Dicer cleaves the pre-miRNA of which only one strand (known as guide strand) is incorporated into the RNA-induced silencing complex (RISC), the cytoplasmic effector machine of miRNA. The passenger strand is subsequently degraded [28]. The RISC is comprised of Dicer, double-stranded RNA-binding factor, and Argonaut protein 2 (Ago2). The posttranscriptional RNA silencing is facilitated via imperfect complementary binding of miRNA attached to RISC, to the respective mRNA 3'UTR, resulting in translational inhibition [29]. Additionally, miRNAs are selectively excreted via lipoproteins or microvesicles, potentially functioning as a mode of intercellular communication. This last notion is important in relation to the nature of sampling material in the sense that plasma miRNA patterns might be a useful diagnostic and/or prognostic marker of ongoing pathological processes [30, 31]. For a more comprehensive review of miRNA biogenesis, please refer to Winter et al. [26].

\section{MicroRNA Expression in Glioblastoma Multiforme}

miRNAs can be regarded as cancer biomarkers when their variation in expression identifies the cancerous state. To date, almost all tumor tissue analyzed by miRNA profiling has provided distinct miRNA profiles compared to normal tissue [32]. These differential profiles can be further associated with prognostic factors and disease progression [33-35]. In GBM, the number of studies pertaining to miRNA expression and functional characterization has grown and miRNA signatures are refining GBM classification, differentiating between the different grades and stages, providing key regulatory links to disrupted signaling pathways such as those facilitating cell growth. This has lead to a more in depth understanding about GBM pathology [36].

Early studies show that miRNA expression in tumor samples seems lower, and this could be a function of cellular differentiation status [32, 37]. It appears that the most common dysregulation of miRNA in GBM is observed to be overexpression, based on the systematic literature review published by Møller et al. Here, for example, miR-17, miR-21, miR-93, miR-221, and miR-222 have been intensively investigated with respect to both their expression and functionality, but the functional properties of the vast majority remains completely unknown [38]. The most extensively investigated miRNA is miR-21, which is consistently reported to be overexpressed in GBM in a grade-specific manner [12, 39-68]. At least for GBM, miR-21 appears to be the major anti-apoptotic and pro-survival factor that is linked to shorter progression-free survival [12, 69, 70].

Expression profiling of miRNA in patient tissue and investigation of their putative function using in vitro primary cultures and in vivo studies have provided an insight not only into the genes that are regulated by respective miRNA, but also the pathways that are disrupted, many of which are hallmarks of GBM biology (reviewed by Lakomy et al. [12]). The pattern of miRNA expression, whether its up or downregulation, is now becoming a recognized tool in addition to gene expression profiling to stratify GBM patients into different groups [36]. Here, the miRNA cohorts are smaller and miRNA signatures pertaining to overall or progression-free survival are starting to evolve, albeit they are still very much dependent on the individual patient history, tumor size, age, and treatment regimen.

Overall and Progression-Free Survival as Clinical Endpoints in Glioblastoma Multiforme

In the literature, both overall survival (OS) and progressionfree survival (PFS) are widely used end points to assess the predictive factor of a given miRNA signature; however, the two terms do not provide equal information [71-73]. When evaluating a treatment response, OS is used as a measure of the end result including the complete disease history and possible other factors affecting the lifespan. The PFS is more specific in its measure of the effect of a specific treatment in the form of tumor control or radiographic response. Reviewing the literature and trying to draw conclusions are therefore challenging when both OS and PFS are applied [74]. The response assessment criteria for GBM has been developed over the course of several decades as a result of technology advances in imaging and expanded knowledge on tumor biology. Before 1990, the Levin and WHO Oncology Response Criteria, which primarily was based on contrastenhanced computer tomography, was the standard assessment methods [75]. These were substituted by the standardized McDonald Criteria, which took into account that contrast enhancement could be affected by clinical factors such as the use of corticosteroids [76]. The McDonald Criteria incorporated the clinical assessment (neurology status) of the patient in the designation of response to therapy as being a complete response, partial response, or stable or progressive disease. With the arrival of magnetic resonance imaging and new therapeutic options, the response assessment criteria was developed further and standardized with regard to all aspects of imaging, timing, and evaluation techniques. Especially the introduction of bevacizumab, a monoclonal antibody targeting VEGF-A and a resulting increased risk of pseudoprogression interpreted as disease progression stimulated the modification and lead to the Revised Assessment in Neuro-Oncology (RANO) Criteria in 2010 [77-80]. Because of this 
development over the last 20 years, caution should be taken in the comparison of particular PFS data.

Aim of the Review

This review is aimed at providing an up-to-date account of the miRNA expression profiles in tumor tissue associated with prognosis and survival in GBM. It is meant as an updatable list of studies and signatures that have been linked to the progression of GBM, to give an account of the miRNAs, which have been reported to be suitable as a prognostic factor for short- or long-term survival. Plasma miRNA expression has also been associated with survival in GBM, but this is not within the scope of this review [25]. Based on the literature, the studies are stratified into those based on publicly available databases and those conducted on independent tissue cohorts. These data sets have been extensively reviewed and combined to derive a signature or pattern of miRNAs, which has a prognostic potential. The miRNAs reported to have a protective or riskassociated profile have been highlighted in relation to GBM. Finally, the studies that have reported a miRNA signature with respect to prognosis have been compared to find common miRNA profile across the different studies.

\section{Methodology and Delimitations}

A Medline database search on "microRNA, glioblastoma, survival, prognosis and progression" (typed: "(microRNA OR miRNA) AND (glioblastoma OR glioma) AND (survival OR prognosis OR progression)") was performed (date of last search entry: November $26,2013)$. The results contained a total of 270 papers; 125 of these were chosen based on title and abstract content. Of the remaining, 100 papers were cell culture studies and 45 were reviews or review like and were therefore excluded. A total of 125 papers were reviewed for miRNA expression level in GBM correlated to survival and/or progression, 25 involved database studies, and 35 contained studies on GBM tissue (not databasederived). The miRNA profiles, often presented in the form of signatures, were extracted from the papers. This review summarizes the studies investigating miRNAs in GBM and explores their correlation to clinical outcome and highlights the functional characteristics of the miRNAs linked to protection (i.e., longer survival) or risk (i.e., shorter survival). The miRNAs that are included in the signature of more than one study and involved in the progression of GBM have been identified, and their functional role, if known, is discussed.

\section{Prognostic MicroRNA Signatures in Glioblastoma Multiforme}

\author{
MicroRNA Signatures Derived from Database Mining
}

A total of 25 studies were based on database entries. For the individual studies, the database accessed, cohort size, cohort factor, and normalization methodology along with miRNA signature were documented (Table 1). The majority of the studies used The Cancer Genome Atlas (TCGA) (http:// cancergenome.nih.gov). However, four studies used the Chinese Glioma Genome Atlas (CGGA) (http://www.cgga. org.cn), which uses the Illumina Human v2.0 miRNA Expression BeadChip microarray platform [11, 81-83]. The study by Ma et al evaluated two large cohorts of data, the CGGA with 198 samples containing low-grade gliomas and 91 GBMs and an additional cohort of 128 samples, with lowgrade gliomas and $68 \mathrm{GBMs}$ to validate the array data. High expression of miR-196b was conferring poor prognosis when stratifying the patients into high miR-196b expression and low miR-196b expression groups [82]. Following a similar experimental setup, Wu et al. looked at $91 \mathrm{GBM}$ patients taken from the array data and validated their findings in a cohort of 60 GBM patients. Here, they focused on miR-328, showing that a low level of expression was conferring poor prognosis [83]. The TCGA dataset has also been used for developing a new method for predicting the outcome based on miRNA expression; however, only one of the studies provided the miRNA identified [84].

While a few studies gave rise to a defined multiple-miRNA signature, eight of the studies looked at a single miRNA. For example, two studies evaluated the functionally wellcharacterized miRNA, miR-10b. Gabriely et al. showed that miR-10b was expressed in GBM tissue while not present in normal brain tissues. Using TCGA data, they investigated the association between the expression of miR-10b and clinical outcome and found that miR-10b correlated with survival although with stratified conditions, the association was insignificant. When the correlation with survival for miR-10b was assessed together with miR-10a, however, the association with survival was significant regardless of stratification; hence, high levels of miR-10 conferred poor survival [85]. Guessous et al. also found a correlation between high levels of miR-10b and poor survival by analyzing the TCGA data and further reported on a functional role of miR-10b in GBM stem cells [86].

Since the majority of the studies use the TCGA dataset in analyzing the expression of miRNAs in GBM, the platform for generating the data was the same. The only differences seen were in the downstream analysis, other clinically prognostic factors, and the type of filtering applied. Expression analysis was conducted on Agilent $8 \times 15 \mathrm{~K}$ Human miRNA microarrays, with data available at four levels. The first level 


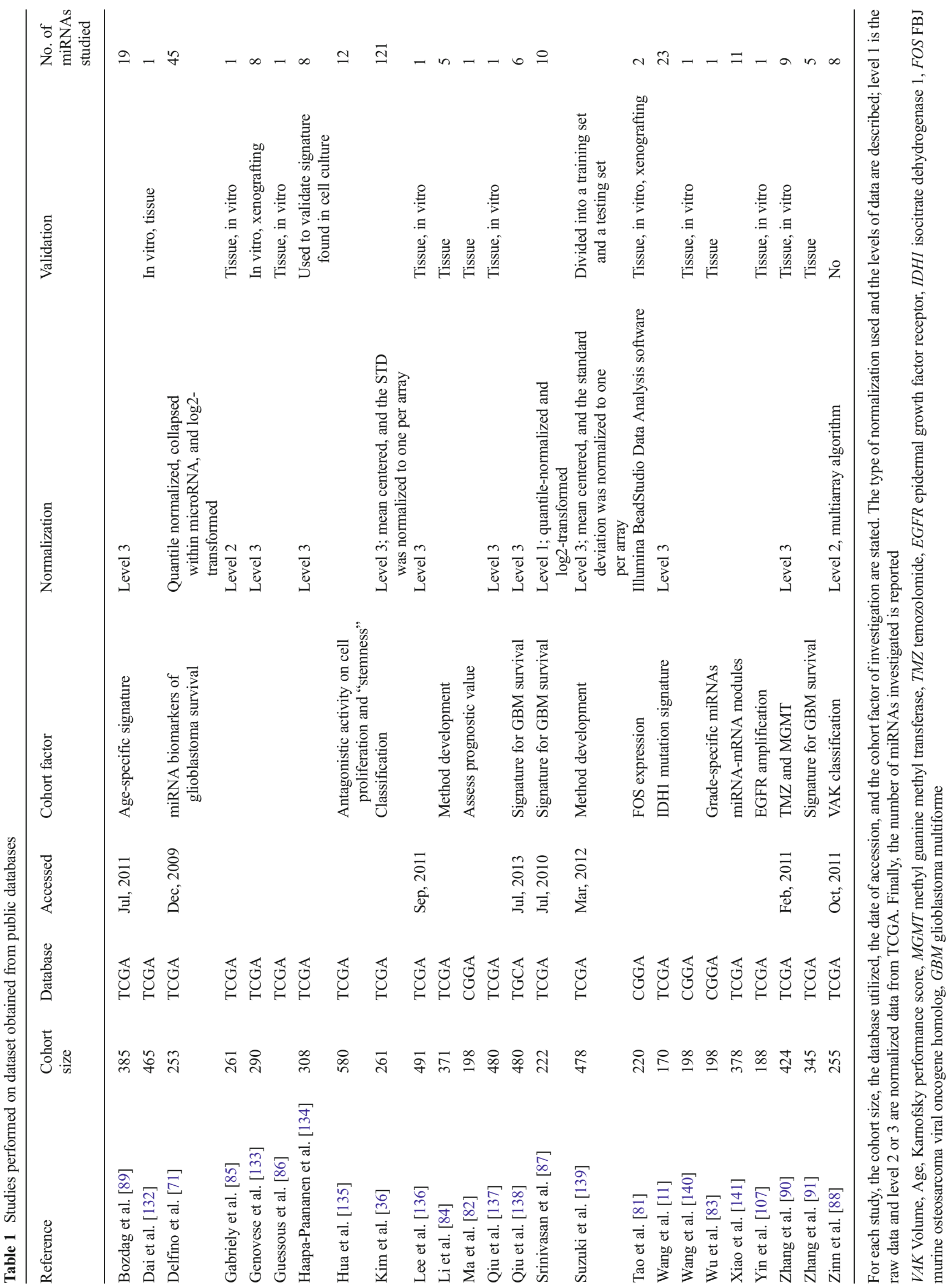


is the raw non-normalized data from the array (level 1), and the second level (level 2) is the processed normalized signal. The third level (level 3) is the segmented data, assemblies of the processed data from single samples, and grouped by probed loci to form larger contiguous regions. The fourth level (level 4) is the summary, a quantified association across classes of samples and associations based on molecular abnormalities, sample characteristics, and/or clinical variability. Not all studies state the level of data they use, but most use the third level. Only one study, looking at a ten-miRNA signature, used level 1 and quantile-normalized the expression data. Here, they segregated patients in to high- and low-risk groups and identified seven miRNAs associated with high risk of disease progression and three miRNAs that were found to be protective [87]. A more elaborate study by Delfino et al. used quantile-normalized data (although it does not specify the level of the data set analyzed) and identified 45 miRNAs in the TCGA data across race, gender, recurrence, and therapy linked to survival [71]. Using level 2 data with multiarray algorithm normalization, Zinn et al. looked at 78 patients and included a Volume (tumor volume), Age, and Karnofsky Performance Score (VAK) classification to dichotomize the patients into VAK A (good prognosis) and VAK B (poor prognosis). A total of five miRNAs were associated with short-term survival (miR-566, miR-505, miR-345, miR-484, and miR-92b), and three miRNAs were associated with longterm survival (miR-511, miR-369-3p, and miR-655) [88].

Though the normalization was not standard for all studies along with the variation in cohort size, most of them used normalized data from the TCGA database and therefore had the same material. The cohort size, however, ranges from 170 to 580 (mean=329 \pm 121 ) and is a function of the cohort factors that are investigated. For example, factors such as age, grade, MGMT methylation, chemotherapy regimen, IDH1 mutation, or grade sub-classification are just some examples of where the investigation is based on prior knowledge of clinical data correlated with expression and survival $[11,36,83,89,90]$. In addition to the TCGA, a number of the studies have used independent GBM tissue validation cohorts for identifying differentially expressed miRNAs with respect to cohort factors $[82,83,91]$.

\section{MicroRNA Signatures Derived from Independent Tissue Cohorts}

The studies performed on independent sample sets can generally be characterized as being validation of database findings, validation of literature findings, or novel array-based determination of miRNA profiles of clinical interest in GBM (Table 2). A total of 35 studies identified miRNA signatures associated to survival, and many of these have used tissues to validate signatures previously found in datasets described in the last section and contained in Table 1 . The majority of studies $(n=30)$ use PCR-based methods when validating miRNA expression, while several studies use different types of arrays. The PCR-based methods require normalization, and most of the studies use RNU6B, though there are a few studies that use others, such as hsa-miR-16 or RNU5A [51, 92].

The starting material used in the studies was either tissue or formalin-fixed paraffin-embedded (FFPE) tissue with a variable cohort size $(\min =12, \max =253$, mean $=91 \pm 59)$. With regard to sample preparation, de Biase et al. have shown that there is no difference in the miRNA expression obtained from tissue and FFPE tissue, and some studies also use both types to validate their findings [93]. Twenty-five studies focused on single-miRNA candidates, while the remainder focused on expression profiles of several miRNAs $(\min =1, \max =30$, mean $=3 \pm 5$ ).

While most of the studies focus on smaller miRNAs signatures, Niyazi et al. present a larger cohort of miRNA as a putative survival signature. They used a top-down approach, where they filtered the miRNAs based on the variance in expression across the samples and chose the 30 most dysregulated miRNAs. These miRNAs were used to stratify the samples into two patterns, which correlated with short- and long-term survival [94]. This approach was also applied in several database studies, limiting the number of miRNAs down to a specific signature $[51,84,90,91]$. Others looked at pre-selected miRNAs already linked to GBM pathogenesis in the literature [92, 95, 96]. Zhang et al. found that miR-221 and miR-222 expression was significantly increased in high-grade gliomas compared with low grade, positively correlated with degree of glioma infiltration. This corresponded well to the fact that overexpression of miR-221 and miR-222 increased cell invasion [12]. In addition, Quintavalle et al. showed that miR-221 and miR-222 were upregulated in GBM patients and that they target MGMT mRNA thereby inducing greater temozolomide-mediated cell death [92].

Of all the studies, 12 of them utilized both databases and independent tissue cohorts. They all link an expression of one or more miRNAs to survival; however, some studies categorize a given miRNA to be protective or riskassociated. Three studies used hazard ratio to assess whether a specific miRNA was protective or risk-associated, while Wang et al. used a Significance analysis of microarray (SAM) and $\mathrm{Li}$ et al. used the Cox-regression coefficient to designate the miRNAs $[11,84,87,90]$. Interestingly, large variations can be found in the choice of control tissues across the individual studies, ranging from purchased RNA from normal brains to tissues from epilepsy patients or patients with cerebral trauma. Such differences in control tissues might also be a factor in the incoherency between the miRNA signatures found in the different studies (Table 2). In addition, only few studies specify their use of the terms OS and PFS, which also makes direct comparison difficult. 


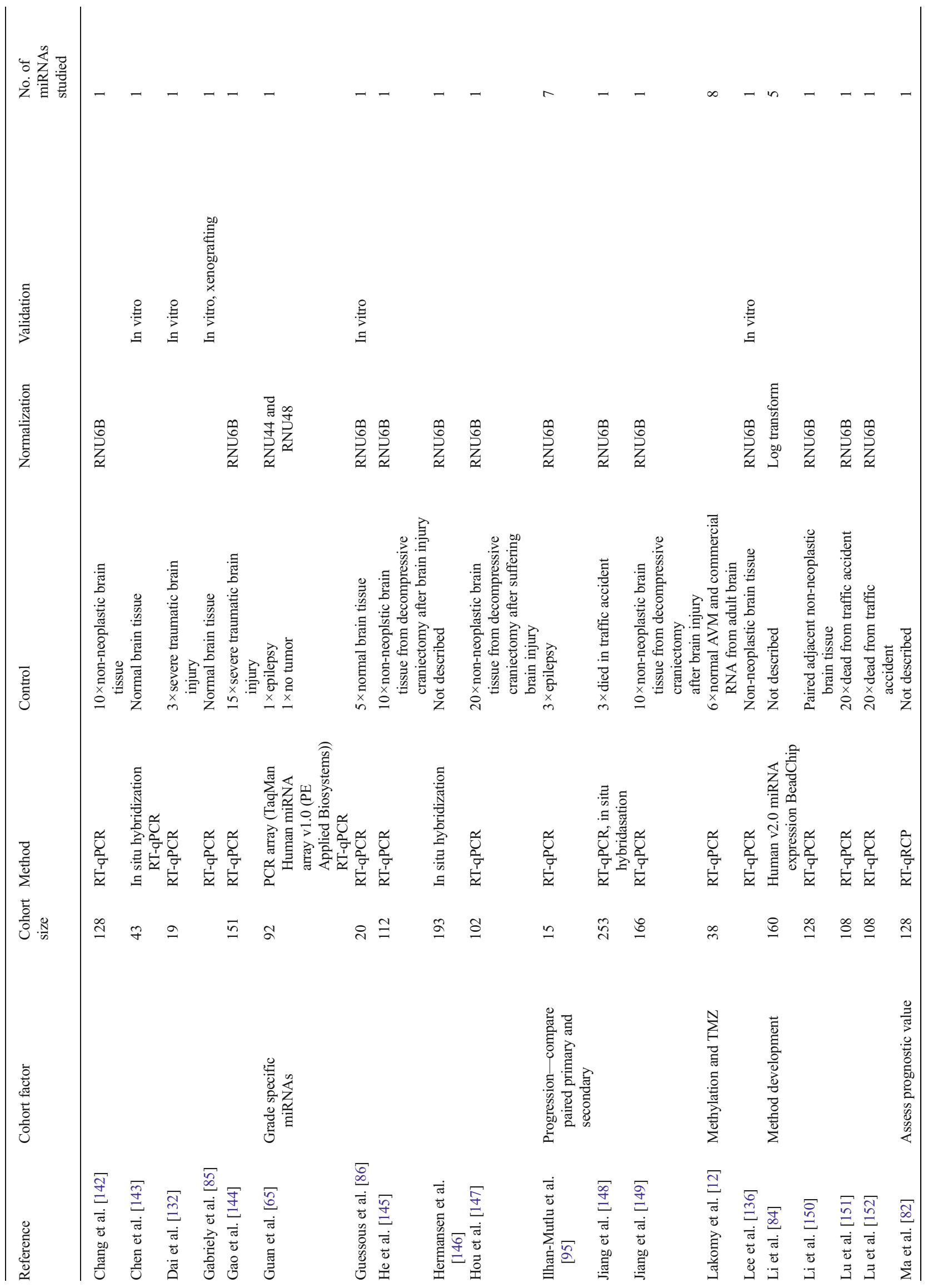




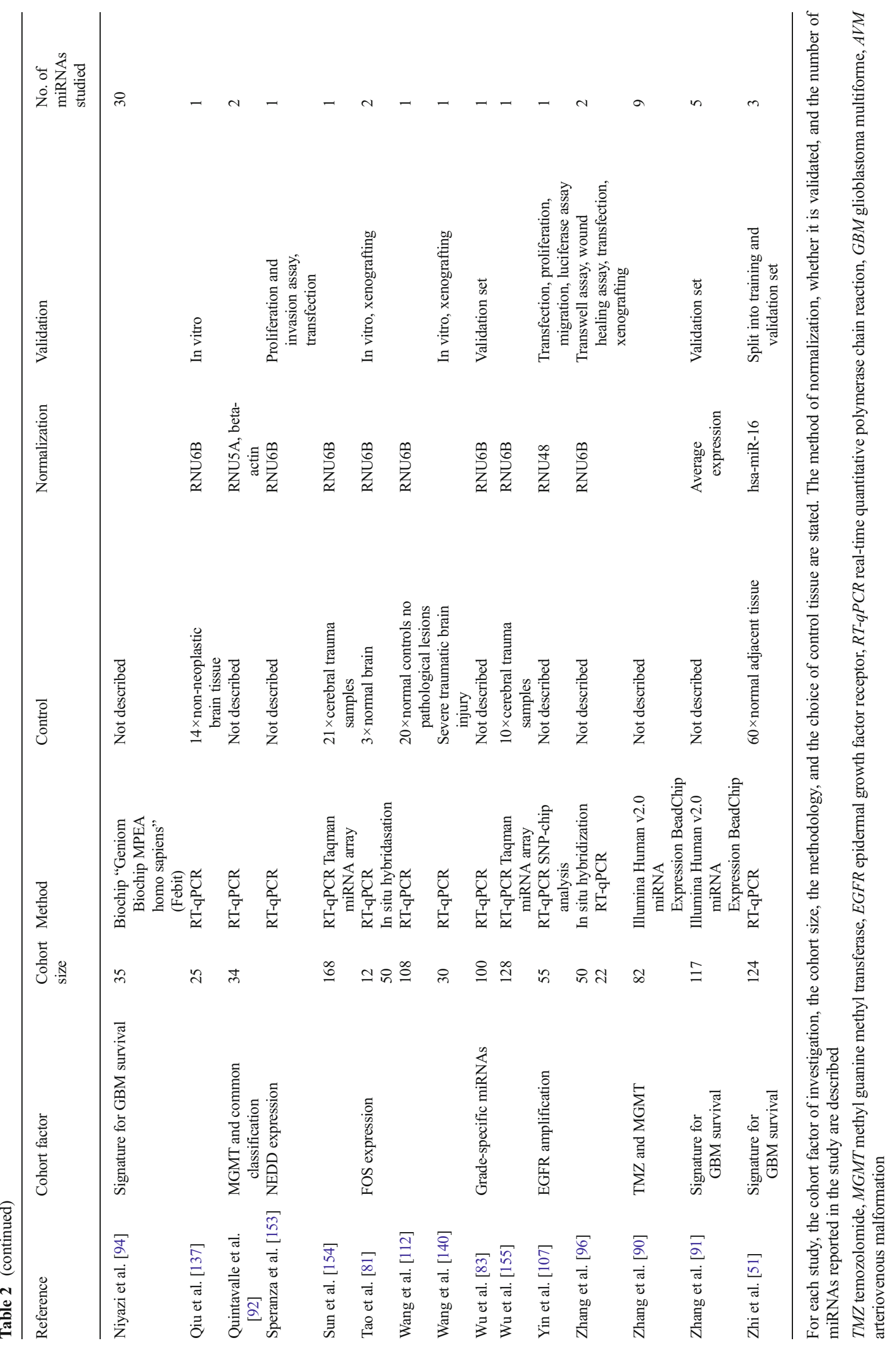




\section{MicroRNA Reported to be Protective or Risk-Associated}

A number of studies provided miRNA signatures associated with survival or progression in GBM and reported that individual miRNAs of these signatures could be regarded as either protective or risk-associated. These miRNAs and their functional role in GBM pathogenesis and progression are presented in Table 3.

\section{Clinically Protective MicroRNAs}

In the group of the protective miRNAs $(n=22)$, only two miRNAs, miR-544 and miR-1227, have not been described previously in relation to miRNA alterations in GBM pathogenesis. Eleven of the protective miRNAs were significantly increased in studies comparing GBM specimens to normal brain tissue, while only six were significantly downregulated. Surprisingly, three of these miRNAs are well described as miRNAs with an oncogenic potential and have several validated targets considered to be tumor suppressor genes. This includes the extensively investigated miR-17-5p, which in vitro has been shown to increase angiogenesis and growth when overexpressed and decrease viability and proliferation when inhibited, making it unlikely that this miRNA, at least solely, should be considered protective [97]. As to miR-19a, miR-19b, and miR-106a, there is currently an inconsistency in the literature regarding their role in GBM development. The functional data available on miR-106a shows that overexpression by transfection of GBM cell lines causes a significant decrease in proliferation and an increase in apoptosis, likely mediated by the suppression of E2F1, supporting the notion of it being tumor suppressive [98]. More in line with what would be expected, miRNAs with previously investigated tumor suppressive capabilities are present on the list whereby miR128a and miR-181d are most notable. miR-128 has been investigated in 13 studies demonstrating its wide range of oncogenic mRNA targets and its ability to inhibit angiogenesis and proliferation and even to significantly decrease total tumor volume in vivo [12, 40-42, 48, 56, 62, 66, 67, 99-103]. Similarly, although, less extensively investigated is miR$181 \mathrm{~d}$, which has been shown to target the oncogenes Bcl-2 and K-Ras whereby apoptosis is increased and proliferation decreased. miR-181d transfection is demonstrated to decrease in vivo tumor size and has been shown to increase the susceptibility to the chemotherapeutic agent, temozolomide [104, 105].

\section{Risk-Associated MicroRNAs}

Within the cohort of miRNAs described as risk-associated $(n=22)$, nine have not been previously associated with miRNA modulation in GBM. Of the 13 miRNAs mentioned in the literature, ten are overexpressed in GBM specimen, three are underexpressed, and four have been functionally characterized. miR-34a is well studied in numerous GBM cell lines and shown to increase cell differentiation and decrease total tumor volume in a xenograft mouse model of GBM [106, 107]. The less investigated miR-146b is similarly known to decrease in vitro invasiveness, migration, proliferation, and tumor volume in mice $[108,109]$. Both miR-34a and miR$146 \mathrm{~b}$ are, in terms of isolated functional characteristics, not associated with risk of GBM progression (Table 3). The oncogenic miRNAs, miR-221 and miR-222, clinically associated with risk, have been studied in relation to a diverse list of cancers including GBM. They inhibit a number of common gene targets such as PUMA and P57 both involved in apoptosis. When overexpressed in vitro, both miR-221 and miR222 potentiate classic cancer hallmarks, i.e., proliferation, angiogenesis, and invasion. In vivo studies have revealed that miR-221 or miR-222 overexpression is associated with increased tumor growth, a situation that can be reversed with administration of corresponding antagomirs $[110,111]$.

Out of 44 miRNAs reported to be protective or riskassociated, only eight were not previously described as significantly modulated in GBM samples. This demonstrates a relatively broad coverage in terms of the miRNAs investigated purely to assess miRNA modulation in GBM pathogenesis without correlating the data to clinical outcome (Table 3). No general patterns apply to these cohorts of protective and riskassociated miRNAs, as such, several miRNAs, which are described as oncogenic from a functional standpoint, are present within the cohort of protective miRNAs and vice versa. This comparison between in vitro functionality and clinical implication of GBM-related miRNAs illustrates that although a specific miRNA may have a specific set of functional characteristics when artificially over or underexpressed in isolated in vitro models, this is not necessarily a good indicator for the multifactorial clinical progression of GBM. For more elaborate details of the functional characterization of miRNAs involved in GBM, please refer to Møller et al. [38].

\section{MicroRNAs Included in Several Signatures}

Based on the multiple-miRNA signatures identified from both tissue and database studies pertaining to survival, the miRNAs found in multiple studies were identified (Table 4). Most of the miRNA found in signatures are specific for the given study. Thirteen of the miRNAs were identified in more than one study; however, no miRNAs were identified in more than three studies. Through miRNA array analysis, Niyazi et al. found a 30-miRNA signature in an independent cohort, which divided the samples into short- and long-term survival [94]. Furthermore, Zhang et al. and Srinivasan et al. used similar methods and the same database, but the overlap between these studies was poor $[87,91]$. 
Table 3 miRNAs reported to be protective or risk-associated

\begin{tabular}{|c|c|c|c|c|}
\hline miRNA & Reference & Function in GBM & Validated targets & Reference \\
\hline hsa-miR-9 & [112] & $\begin{array}{l}\text { Overexpressed (5), } \\
\text { oncogenic properties }\end{array}$ & CAMTA1 & {$[39,40,64,66,156]$} \\
\hline hsa-miR-17-5p & {$[87,112]$} & $\begin{array}{l}\text { Overexpressed (9), } \\
\text { oncogenic properties }\end{array}$ & $\begin{array}{l}\text { POLD2, TGF } \beta \text {-RII, CTGF, } \\
\text { CAMTA1, PTEN }\end{array}$ & {$[39,40,42,66,67,97,156,157]$} \\
\hline$h s a-m i R-19 a$ & {$[112]$} & Disputed expression in GBM (6) & CTGF & {$[39,42,66,67,97,157]$} \\
\hline hsa-miR-19b & [112] & Disputed expression in GBM (4) & & {$[42,66,67,157]$} \\
\hline hsa-miR-20a & {$[87,112]$} & $\begin{array}{l}\text { Overexpressed (5), } \\
\text { oncogenic properties }\end{array}$ & TGF $\beta$-RII, CTGF & {$[39,40,42,67,97]$} \\
\hline hsa-miR-99a & [112] & $\begin{array}{l}\text { Overexpressed (2), } \\
\text { oncogenic properties }\end{array}$ & & {$[66,67]$} \\
\hline hsa-miR-106a & {$[87,112]$} & Disputed expression in GBM (5) & $\mathrm{E} 2 \mathrm{~F} 1$ & {$[42,48,51,66,98]$} \\
\hline hsa-miR-128a & [112] & $\begin{array}{l}\text { Underexpressed (13), } \\
\text { tumor suppressive }\end{array}$ & $\begin{array}{l}\text { WEE1, p70S6K1, Msi1, } \\
\text { E2F3a, Bmi-1, } \\
\text { EGFR, PDGFR } \alpha\end{array}$ & {$[12,40-42,48,56,62,66,67,99-103]$} \\
\hline hsa-miR-128b & {$[112]$} & Underexpressed (7) & WEE1 & {$[41,42,48,56,62,67,158]$} \\
\hline hsa-miR-139 & {$[112,159]$} & Underexpressed (5) & & {$[40,42,60,67,158]$} \\
\hline hsa-miR-181d & {$[90,160]$} & $\begin{array}{l}\text { Underexpressed (1), } \\
\text { tumor suppressive }\end{array}$ & Bcl-2, K-Ras & {$[104,105]$} \\
\hline hsa-miR-183 & {$[112]$} & Underexpressed (2) & & {$[42,64,67,148,161]$} \\
\hline hsa-miR-217 & [112] & Overexpressed (2) & & {$[42,67]$} \\
\hline hsa-miR-301 & [112] & Overexpressed (2) & & {$[42,67]$} \\
\hline$h s a-m i R-324-5 p$ & [112] & Overexpressed (1) & & {$[56]$} \\
\hline hsa-miR-328 & {$[83]$} & Underexpressed (2) & & {$[39,42]$} \\
\hline hsa-miR-374 & [112] & Overexpressed (1) & & {$[40,66]$} \\
\hline hsa-miR-497 & [112] & Overexpressed (1) & & {$[67]$} \\
\hline$h s a-m i R-524-5 p$ & {$[84,90]$} & Overexpressed (1) & & {$[67]$} \\
\hline hsa-miR-544 & {$[84]$} & Overexpressed (1) & & {$[67]$} \\
\hline$h s a-m i R-628-5 p$ & {$[84]$} & & & {$[66]$} \\
\hline hsa-miR-1227 & {$[90]$} & No studies & & \\
\hline hsa-miR-15a & [159] & Overexpressed (4) & & {$[39,62,66,67]$} \\
\hline hsa-miR-31 & {$[87]$} & No studies & & \\
\hline hsa-miR-34a & [112] & $\begin{array}{l}\text { Underexpressed (5), } \\
\text { tumor suppressive }\end{array}$ & $\begin{array}{l}\text { SIRT1, c-Met, Notch1/2, } \\
\text { PDGFRA, Msi1 }\end{array}$ & {$[100,106,162-164]$} \\
\hline hsa-miR-34b & [112] & No studies & & \\
\hline hsa-miR-146b & {$[87]$} & $\begin{array}{l}\text { Underexpressed (5), } \\
\text { tumor suppressive }\end{array}$ & & {$[108,109]$} \\
\hline hsa-miR-148a & {$[87,112]$} & Overexpressed (1) & & {$[64]$} \\
\hline hsa-miR-155 & [112] & Overexpressed (6) & & {$[40,42,45,66,67,165]$} \\
\hline hsa-miR-193a & {$[87]$} & Overexpressed (1) & & {$[42,67]$} \\
\hline hsa-miR-200b & {$[87]$} & Overexpressed (2) & & {$[67]$} \\
\hline hsa-miR-221 & {$[87,112]$} & $\begin{array}{l}\text { Overexpressed (11), } \\
\text { oncogenic properties }\end{array}$ & $\begin{array}{l}\text { P27, Akt, PUMA, P57, } \\
\text { PTP } \mu, \text { Cx43, TIMP3, } \\
\text { MGMT }\end{array}$ & {$[41,48,62,63,110,111,113,166-169]$} \\
\hline hsa-miR-222 & {$[87,112]$} & $\begin{array}{l}\text { Overexpressed (9), } \\
\text { oncogenic properties }\end{array}$ & $\begin{array}{l}\text { P27, Akt, PUMA, P57, } \\
\text { PTP } \mu, \text { Cx43, TIMP3, } \\
\text { MGMT }\end{array}$ & {$[41,48,62,110,111,166-169]$} \\
\hline hsa-miR-297 & [91] & No studies & & \\
\hline hsa-miR-299-3p & [91] & Underexpressed (1) & & {$[42]$} \\
\hline hsa-miR-346 & [91] & No studies & & \\
\hline hsa-miR-518b & [91] & Overexpressed (1) & & {$[67]$} \\
\hline hsa-miR-541* & {$[91]$} & No studies & & \\
\hline hsa-miR-551a & [91] & No studies & & \\
\hline hsa-miR-566 & [91] & Overexpressed (1) & & {$[67]$} \\
\hline hsa-miR-661 & {$[91]$} & Overexpressed (1) & & {$[67]$} \\
\hline
\end{tabular}


Table 3 (continued)

\begin{tabular}{lllll}
\hline miRNA & Reference & Function in GBM & Validated targets & Reference \\
\hline hsa-miR-768-3p & {$[112]$} & Overexpressed (1) & [67] \\
hsa-miR-936 & {$[91]$} & No studies & \\
hsa-miR-1238 & {$[91]$} & No studies & \\
\hline
\end{tabular}

MicroRNAs described as either protective (ital) or risk-associated (bold) compared with their corresponding functional characteristics. The terms overexpressed and underexpressed refers to miRNA expression data comparing GBM samples to normal brain tissue. Disputed expression signifies that different studies present contradictory results. The numbered parentheses are numbers of studies supporting the observation

It is striking that the database studies do not reveal better coherency; however, this could be attributed to the cohort factors studied or the filtering of the miRNAs during the analysis. The tissue studies represent independent cohorts; however, many of the database studies have validated their results in independent cohorts, whereby the cohort factors could be the prime source for the lack of overlap. Additionally, Ilhan-Mutlu et al. chose to investigate seven well-characterized miRNAs (miR-10b, miR-21, miR-181b, miR-181c, miR-195, miR-221, miR-222) and found that none of them correlated with survival [95] contradicting other studies $[87,112]$. Therefore, the 13 miRNAs identified in more than one signature could be more applicable in their prediction of survival and of great interest in relation to GBM prognosis.

Functional Analysis of the MicroRNAs Included in Several Signatures

The majority of the 13 miRNAs included in more than one signature have been functionally characterized in GBM and associated with the expression of validated target genes (Table 5). The most well-characterized miRNA in GBM is miR-21, which functions as an oncogenic miRNA. miR-21 has numerous validated target genes that it represses in GBM and therefore it is interesting that this miRNA is included in two signatures. The target genes of miR-21 include genes associated with proliferation (e.g., PTEN and PDCD4), invasiveness (e.g. TIMP3 and RECK), and susceptibility to chemo and radiation therapy (e.g., hMSH2), factors, which are all characteristics of GBM tumors [44, 48, 59, 70]. The same characteristics of GBM tumor growth are also modulated by miR-221 and miR-222, both of which appear in three signatures. Being less well characterized than miR-21, miR-221 and miR-222 still have several validated target genes including some important tumor suppressor genes such as P27, P57, TIMP3, and Cx43 [96, 111, 113, 114].

In addition to the oncogenic miRNAs identified in more than one signature, different tumor suppressor miRNAs were also found in several signatures. miR-195 has validated target genes, including some cyclins and E2F3, which are associated with cell proliferation $[115,116]$. Hence, a low expression of this miRNA should in theory correlate with a favorable clinical outcome, which is in fact reflected in the clinical data [12]. Another interesting miRNA shown in more than one signature is miR-136, which has very little functional characterization, but the current validated target genes include the important oncogene, Bcl-2 [117]. Several of the 13 miRNAs (miR-155, miR-17-5p, miR-181b, miR-195, miR-20a, miR21, miR-221, and miR-222) are known to modulate the mesenchymal mode of migration and invasion (MMMI), which is an important characteristic of GBM cells $[38,118]$. Three of the miRNAs identified in more than one signature have no functional characterization and could possibly reveal numerous relevant target genes to substantiate the importance of the 13 miRNAs in future determination of patient prognosis.

\section{Perspectives on MicroRNA-Based Therapies for the Treatment of Glioblastoma Multiforme}

Given the fact that several miRNA signatures associated with OS or PFS have been identified and that these miRNAs have functional characteristics with importance in GBM progression, a therapeutic concept taking advantage of such correlations seems inherent. The use of miRNA-based therapies in the treatment of GBM is still in its primary phases with exciting basic research being published frequently [119].

Approaches for utilizing miRNAs in such treatment regimens includes both inhibition of oncogenic miRNAs (e.g., miR-21) or overexpression of tumor suppressor miRNAs (e.g., miR-146b) with different types of carriers to facilitate delivery directly to the tumor tissue [120, 121]. Systemic administration of a liposome-encapsulated tumor suppressor miRNA, miR-7, led to a significant tumor size reduction in a xenograft mouse model of GBM. In addition, several key oncogenes were downregulated upon the tumor suppressor miRNA delivery [122]. Another more sophisticated type of lipid-based delivery was exploited by Griveau et al. where locked nucleic acid miRNA inhibitors against miR-21 conferred increased radiosensitivity in U87MG cells [120]. miRNA carriers have also been generated with polymerbased technology, using poly(amido amine) to encapsulate miR-7 for delivery to U251 cells, which resulted in a higher transfection efficiency than liposomal delivery [123]. 
Table 4 miRNA signatures correlating with survival in GBM

\begin{tabular}{|c|c|}
\hline Reference & miRNA \\
\hline Bozdag et al. [89] & $\begin{array}{l}\text { Ebv-miR-BART1-5p, Ebv-miR-BHRF1-2, Hcmv-miR-UL70-5p, hsa-miR-142-3p, hsa-miR-142-5p, hsa-miR-147, } \\
\text { hsa-miR-223, hsa-miR-302c, hsa-miR-325, hsa-miR-422b, hsa-miR-453, hsa-miR-507, hsa-miR-552, hsa-miR-558, } \\
\text { hsa-miR-620, hsa-miR-649, hsa-miR-661 }\end{array}$ \\
\hline Hua et al. [135] & hsa-miR-19a, hsa-miR-93, hsa-miR-221, hsa-miR-222 \\
\hline Lakomy et al. [12] & hsa-miR-21, hsa-miR-128a, hsa-miR-181c, hsa-miR-195, hsa-miR-196a, hsa-miR-196b, hsa-miR-221, hsa-miR-222 \\
\hline Li et al. [84] & hsa-miR-15a, hsa-miR-139-5p, hsa-miR-524-5p, hsa-miR-544, hsa-miR-628-5p \\
\hline Niyazi et al. [94] & $\begin{array}{l}\text { hsa-let-7a, hsa-let-7f, hsa-let-7g, hsa-let-7i, hsa-miR-26a*, hsa-miR-29b, hsa-miR-30b, hsa-miR-124, hsa-miR-129-3p, } \\
\text { hsa-miR-136, hsa-miR-195, hsa-miR-210, hsa-miR-374b, hsa-miR-409-3p, hsa-miR-487b, hsa-miR-539, hsa-miR-555, } \\
\text { hsa-miR-578, hsa-miR-590-3p, hsa-miR-595, hsa-miR-720, hsa-miR-1260, hsa-miR-1282, hsa-miR-1286, hsa-miR- } \\
\text { 1305, hsa-miR-2113, hsa-miR-3065-3p, hsa-miR-3132, hsa-miR-3163, hsa-miR-4286 }\end{array}$ \\
\hline Qiu et al. [138] & hsa-miR-130a, hsa-miR-155, hsa-miR-210, hsa-miR-323, hsa-miR-326, hsa-miR-329 \\
\hline Srinivasan et al. [87] & $\begin{array}{l}\text { hsa-miR-17-5p, hsa-miR-20a, hsa-miR-31, hsa-miR-106a, hsa-miR-146b, hsa-miR-148a, hsa-miR-193a, hsa-miR-200b, } \\
\text { hsa-miR-221, hsa-miR-222 }\end{array}$ \\
\hline Wang et al. [11] & $\begin{array}{l}\text { hsa-miR-9, hsa-miR-17-5p, hsa-miR-19a, hsa-miR-19b, hsa-miR-20a, hsa-miR-34a, hsa-miR-34b, hsa-miR-99a, } \\
\text { hsa-miR-106a, hsa-miR-128a, hsa-miR-128b, hsa-miR-139, hsa-miR-148a, hsa-miR-155, hsa-miR-183, hsa-miR-217, } \\
\text { hsa-miR-221, hsa-miR-222, hsa-miR-301, hsa-miR-324-5p, hsa-miR-374, hsa-miR-497, hsa-miR-768-3p }\end{array}$ \\
\hline Zhang et al. [90] & $\begin{array}{l}\text { hsa-miR-181d, hsa-miR-297, hsa-miR-299-3p, hsa-miR-346, hsa-miR-541*, hsa-miR-551a, hsa-miR-661, hsa-miR-936, } \\
\text { hsa-miR-1238 }\end{array}$ \\
\hline Zhang et al. [91] & hsa-miR-181d, hsa-miR-566, hsa-miR-524-5p, hsa-miR-518b, hsa-miR-1227 \\
\hline Zhi et al. [51] & hsa-miR-21, hsa-miR-106a, hsa-miR-181b \\
\hline Zinn et al. [88] & hsa-miR-92b, hsa-miR-345, hsa-miR-369-3p, hsa-miR-484, hsa-miR-505, hsa-miR-511, hsa-miR-566, hsa-miR-655 \\
\hline
\end{tabular}

Overview of the miRNA signatures reported in database studies and independent tissue cohort studies correlated with survival or progression of GBM. The miRNAs marked in ital were detected in two or more studies

Of particular interest in solving the problems with efficient drug delivery to the brain, both in malignancies and neurodegenerative diseases are the use of exosomes as drug carriers [124]. Exosomes are endogenous vesicular structures with a diameter ranging from 40 to $120 \mathrm{~nm}$ produced by all cells in the body [125]. They are characterized by expression of specific proteins in the membrane (especially tetraspanins) and their ability to deliver proteins, mRNA and miRNAs [126]. The delivered mRNAs and miRNAs are fully functional and can be translated into protein or inhibit mRNA targets in the recipient cells $[127,128]$.

The potential of exosomes to deliver functional RNAs to cells was utilized by Alvarez-Erviti et al., who provided interesting evidence as to how exosomes might be used to deliver drugs across the ever troubling blood-brain barrier. Immature dendritic cells were transfected to produce exosomes that expressed a neuron-specific targeting peptide on their surfaces to facilitate specific delivery of the exosome cargo. These exosomes successfully delivered both GAPDHand BACE1-siRNA across the blood-brain barrier resulting in specific gene silencing in the neuronal tissue [129]. Using a somewhat similar approach, Ohno et al. showed that exosomes targeted to EGFR could deliver the tumor suppressor miRNA, let-7a, to a xenograft breast cancer model after intravenous administration. Furthermore, let-7a suppressed the growth of the tumor underscoring the relevance of using exosomal delivery in malignant diseases [130].

Evidence is now emerging showing that exosomal delivery of interfering RNAs could be relevant in the treatment of GBM. GBM cell lines were shown to be resistant to treatment with anti-miRs against the oncogenic miRNA, miR-9, described in Table 3. However, if these GBM cells were co-cultured with anti-miR-transfected mesenchymal stem cells (MSCs) or cultured in the presence of antimiR-transfected MSC-exosomes, miR-9 was significantly downregulated. This decrease in miR-9 expression made the GBM cells more susceptible to treatment with the chemotherapeutic drug, temozolomide [131]. Katakowski et al. also produced exosomes in MSCs, which were transfected with a miR-146b expression vector. The resulting miR-146b-containing exosomes were injected into xenograft GBM tumors, leading to a significant reduction in tumor volume compared to vehicle-treated controls [121]. Interestingly, it has previously been shown that miR-146b negatively correlates with survival in GBM [87]. The use of exosomes in the treatment of GBM may have a great potential and should be substantiated with more evidence including choice of relevant miRNA cargo and direct targeting of GBM cells to facilitate intravenous administration. 
Table 5 Functional characteristics of miRNAs found in several signatures

\begin{tabular}{|c|c|c|c|c|}
\hline microRNA & Validated targets & $\begin{array}{l}\text { Functional role when } \\
\text { 1: overexpressed, } \\
\text { 2: inhibited }\end{array}$ & $\begin{array}{l}\text { No. of signatures } \\
\text { included }\end{array}$ & $\begin{array}{l}\text { Reference to functional } \\
\text { studies }\end{array}$ \\
\hline hsa-miR-106a & E2F1, SLC2A3 & 1: proliferation $\downarrow$, apoptosis $\uparrow$ & 2 & {$[98,132]$} \\
\hline hsa-miR-136 & AEG-1, Bcl-2 & 1: apoptosis $\uparrow$ & 2 & {$[117]$} \\
\hline hsa-miR-148a & No validated targets & No functional analysis performed & 2 & \\
\hline hsa-miR-155 & GABRA-1, FOXO3a & 1: proliferation $\uparrow$, apoptosis $\downarrow$, invasion $\uparrow$ & 3 & {$[170,171]$} \\
\hline hsa-miR-17-5p & $\begin{array}{l}\text { POLD2, TGF } \beta \text {-RII, } \\
\text { CTGF, CAMTA1, } \\
\text { PTEN }\end{array}$ & $\begin{array}{l}\text { 1: angiogenesis } \uparrow \text {, growth } \uparrow, \text { invasion } \uparrow, \\
\text { migration } \uparrow, \text { chemosensitivity } \downarrow \\
\text { 2: viability } \downarrow \text {, apoptosis } \uparrow, \text { proliferation } \downarrow\end{array}$ & 2 & $\begin{array}{c}{[39,97,156} \\
157,172]\end{array}$ \\
\hline hsa-miR-181b & FOS, MEK1, IGF-1R & $\begin{array}{l}\text { 1: xenograft growth } \downarrow \text {, chemosensitivity } \uparrow \text {, } \\
\text { invasion } \downarrow \text {, proliferation } \downarrow \text {, migration } \downarrow\end{array}$ & 2 & {$[81,173,174]$} \\
\hline hsa-miR-195 & $\begin{array}{l}\text { E2F3, CCND3, Cyclin D1, } \\
\text { Cyclin E1 }\end{array}$ & 1: invasion $\downarrow$, proliferation $\downarrow$, xenograft growth $\downarrow$ & 3 & {$[115,116]$} \\
\hline hsa-miR-20a & TGF $\beta$-RII, CTGF & $\begin{array}{l}\text { 1: angiogenesis } \uparrow \text {, growth } \uparrow \\
2 \text { : viability } \downarrow \text {, proliferation } \downarrow\end{array}$ & 2 & {$[97,157]$} \\
\hline hsa-miR-21 & $\begin{array}{l}\text { RECK, TIMP3, APAF1, } \\
\text { ANP32A, SMARCA4, } \\
\text { Caspases, PTEN, Cdc25A, } \\
\text { HNRPK, TAp63, Spry2, } \\
\text { LRRFIP1, PDCD4, hMSH2 }\end{array}$ & $\begin{array}{l}\text { 1: invasiveness } \uparrow \text {, radiosensitivity } \downarrow \\
\text { 2: invasiveness } \downarrow \text {, apoptosis } \uparrow \text {, viability } \downarrow \text {, } \\
\text { proliferation } \downarrow \text {, in vivo tumor volume } \downarrow \text {, } \\
\text { chemosensitivity } \uparrow, \text { radiosensitivity } \uparrow\end{array}$ & 2 & $\begin{array}{l}{[41,43,44,46-50} \\
\quad 52-55,58,59,68 \\
\quad 70,175]\end{array}$ \\
\hline hsa-miR-210 & No validated targets & No functional analysis performed & 2 & \\
\hline hsa-miR-221 & $\begin{array}{l}\text { P27, Akt, PUMA, P57, PTP } \mu, \\
\text { Cx43, TIMP3, MGMT }\end{array}$ & $\begin{array}{l}\text { 1: proliferation } \uparrow, \text { invasiveness } \uparrow, \text { in } \\
\text { vivo tumor volume } \uparrow \text {, apoptosis } \downarrow \text {, } \\
\text { migration } \uparrow \\
\text { 2: proliferation } \downarrow, \text { apoptosis } \uparrow, \text { in vivo } \\
\text { tumor volume } \downarrow \text {, radiosensitivity } \uparrow\end{array}$ & 3 & $\begin{array}{l}{[92,96,110,111,113,114,} \\
\quad 167,168,176]\end{array}$ \\
\hline hsa-miR-222 & $\begin{array}{l}\text { P27, Akt, PUMA, P57, PTP } \mu, \\
\text { Cx43, TIMP3, MGMT }\end{array}$ & $\begin{array}{l}\text { 1: proliferation } \uparrow, \text { invasiveness } \uparrow, \text { in vivo } \\
\quad \text { tumor volume } \uparrow \text {, apoptosis } \downarrow \text {, migration } \uparrow \\
\text { 2: proliferation } \downarrow \text {, apoptosis } \uparrow, \text { in vivo } \\
\text { tumor volume } \downarrow \text {, radiosensitivity } \uparrow\end{array}$ & 3 & $\begin{array}{l}{[92,96,110,111,113,114,} \\
\quad 167,168,176]\end{array}$ \\
\hline hsa-miR-566 & No validated targets & No functional analysis performed & 2 & \\
\hline
\end{tabular}

miRNAs found in several signatures and their functional characteristics. Each miRNA is noted along with their validated targets, their functional role, and how many signatures they appear in. Regarding the functional role, 1 designate the functional role of the miRNA when it is overexpressed and 2 the functional role when it is inhibited in vitro or in vivo

\section{Concluding Remarks}

This review presents the studies investigating the expression of specific miRNAs or miRNA signatures with respect to their correlation to clinical progression of GBM. A large part of the studies utilize data from the same databases (TCGA or CGGA), but they do not necessarily reveal the same results. This is because the extracted data and the filtering based on clinical information differ across individual studies, which makes comparison difficult (Table 1). The studies using individual tissue cohorts also reveal different miRNA signatures with only some consistency between them. Such varying results may be caused by several factors, including miRNAs investigated, type of array platform utilized, cohort size, and especially the choice of control tissue. Comparing miRNA expression data to control tissue obtained from another type of diseased brain (i.e., epilepsy) might be problematic because it may induce variations in the miRNA expression data compared to studies using non-diseased normal brain tissue.
Furthermore, imperfect description of terminology with regard to OS and PFS may also add complexity to the comparison of the different miRNA signatures. Several studies report some miRNAs to have a protective or risk-associated profile with respect to their correlation with clinical outcome in GBM. Interestingly, several of these miRNAs have validated functions in vitro and in vivo, which are opposite to the way that they should mediate either protection or risk. Therefore, the in vitro and in vivo studies available for numerous miRNAs are not necessarily good indicators for the multifactorial clinical progression of GBM (Table 3). However, many of the miRNAs reported to be either protective or riskassociated or the miRNAs included in several signatures do in fact have validated targets and functional characteristics, which are in line with their correlation to clinical progression or survival of GBM (Tables 3, 4, and 5). Having been associated with disease progression or survival in several studies, these miRNAs may be valuable for future determination of patient prognosis and could possibly serve as targets for 
miRNA-based therapies, which hold a great potential in the treatment of this severe malignant disease.

Acknowledgements This research was supported by the Department of Health Science and Technology, Aalborg University, Spar Nord Fonden, and Harboe Fonden.

Open Access This article is distributed under the terms of the Creative Commons Attribution License which permits any use, distribution, and reproduction in any medium, provided the original author(s) and the source are credited.

\section{References}

1. Lima FRS, Kahn SA, Soletti RC et al (2012) Glioblastoma: therapeutic challenges, what lies ahead. Biochim Biophys Acta 1826: 338-349. doi:10.1016/j.bbcan.2012.05.004

2. Dolecek TA, Propp JM, Stroup NE, Kruchko C (2012) CBTRUS statistical report: primary brain and central nervous system tumors diagnosed in the United States in 2005-2009. Neuro-Oncol 14(Suppl 5):v1-v49. doi:10.1093/neuonc/nos218

3. Kanu OO, Mehta A, Di C et al (2009) Glioblastoma multiforme: a review of therapeutic targets. Expert Opin Ther Targets 13:701718. doi:10.1517/14728220902942348

4. He J, Olson JJ, James CD (1995) Lack of p16INK4 or retinoblastoma protein $(\mathrm{pRb})$, or amplification-associated overexpression of cdk4 is observed in distinct subsets of malignant glial tumors and cell lines. Cancer Res 55:4833-4836

5. Watanabe K, Tachibana O, Sata K et al (1996) Overexpression of the EGF receptor and p53 mutations are mutually exclusive in the evolution of primary and secondary glioblastomas. Brain Pathol 6: 217-223, discussion 23-4

6. Verhaak RGW, Hoadley KA, Purdom E et al (2010) Integrated genomic analysis identifies clinically relevant subtypes of glioblastoma characterized by abnormalities in PDGFRA, IDH1, EGFR, and NF1. Cancer Cell 17:98-110. doi:10.1016/j.ccr.2009.12.020

7. Chaudhry NS, Shah AH, Ferraro N et al (2013) Predictors of longterm survival in patients with glioblastoma multiforme: advancements from the last quarter century. Cancer Invest 31:287-308. doi: 10.3109/07357907.2013.789899

8. Hegi ME, Diserens A-C, Gorlia T et al (2005) MGMTGene silencing and benefit from temozolomide in glioblastoma. N Engl J Med 352:997-1003. doi:10.1056/NEJMoa043331

9. Everhard S, Kaloshi G, Crinière E et al (2006) MGMT methylation: a marker of response to temozolomide in low-grade gliomas. Ann Neurol 60:740-743. doi:10.1002/ana.21044

10. Yan H, Parsons DW, Jin G et al (2009) IDH1 and IDH2 mutations in gliomas. N Engl J Med 360:765-773. doi:10.1056/NEJMoa0808710

11. Wang Z, Bao Z, Yan W et al (2013) Isocitrate dehydrogenase 1 (IDH1) mutation-specific microRNA signature predicts favorable prognosis in glioblastoma patients with IDH1 wild type. J Exp Clin Cancer Res 32:59. doi:10.1186/1756-9966-32-59

12. Lakomy R, Sana J, Hankeova S et al (2011) MiR-195, miR-196b, miR-181c, miR-21 expression levels and O-6-methylguanine-DNA methyltransferase methylation status are associated with clinical outcome in glioblastoma patients. Cancer Sci 102:2186-2190. doi: 10.1111/j.1349-7006.2011.02092.x

13. Bartel DP (2009) MicroRNAs: target recognition and regulatory functions. Cell 136:215-233. doi:10.1016/j.cell.2009.01.002

14. Lagos-Quintana M (2001) Identification of novel genes coding for small expressed RNAs. Science 294:853-858. doi:10.1126/science. 1064921
15. Ørom UA, Nielsen FC, Lund AH (2008) MicroRNA-10a binds the 5'UTR of ribosomal protein mRNAs and enhances their translation. Mol Cell 30:460-471. doi:10.1016/j.molcel.2008.05.001

16. Thomson DW, Bracken CP, Goodall GJ (2011) Experimental strategies for microRNA target identification. Nucleic Acids Res 39: 6845-6853. doi:10.1093/nar/gkr330

17. Lee RC, Feinbaum RL, Ambros V (1993) The C. elegans heterochronic gene lin-4 encodes small RNAs with antisense complementarity to lin-14. 75:843-854

18. Pasquinelli AE, Reinhart BJ, Slack F et al (2000) Conservation of the sequence and temporal expression of let-7 heterochronic regulatory RNA. Nature 408:86-89. doi:10.1038/35040556

19. Reinhart BJ, Slack FJ, Basson M et al (2000) The 21-nucleotide let7 RNA regulates developmental timing in Caenorhabditis elegans. Nature 403:901-906. doi:10.1038/35002607

20. Calin GA (2006) MicroRNA-cancer connection: the beginning of a new tale. Cancer Res 66:7390-7394. doi:10.1158/0008-5472.CAN06-0800

21. Madrigal-Matute J, Rotllan N, Aranda JF, Fernández-Hernando C (2013) MicroRNAs and atherosclerosis. Curr Atheroscler Rep 15: 322. doi: $10.1007 / \mathrm{s} 11883-013-0322-\mathrm{Z}$

22. Vickers KC, Rye K-A, Tabet F (2014) MicroRNAs in the onset and development of cardiovascular disease. Clin Sci 126:183-194. doi: 10.1042/CS20130203

23. Zhu S, Pan W, Qian Y (2013) MicroRNA in immunity and autoimmunity. J Mol Med 91:1039-1050. doi:10.1007/s00109-013-1043-Z

24. Abe M, Bonini NM (2013) MicroRNAs and neurodegeneration: role and impact. Trends Cell Biol 23:30-36. doi:10.1016/j.tcb.2012. 08.013

25. Wang Q, Li P, Li A et al (2012) Plasma specific miRNAs as predictive biomarkers for diagnosis and prognosis of glioma. J Exp Clin Cancer Res 31:97. doi:10.1186/1756-9966-31-97

26. Winter J, Jung S, Keller S et al (2009) Many roads to maturity: microRNA biogenesis pathways and their regulation. Nat Cell Biol 11:228-234. doi:10.1038/ncb0309-228

27. Yi R, Qin Y, Macara IG, Cullen BR (2003) Exportin-5 mediates the nuclear export of pre-microRNAs and short hairpin RNAs. 17: 3011-3016. doi:10.1101/gad.1158803

28. Kawamata T, Yoda M, Tomari Y (2011) Multilayer checkpoints for microRNA authenticity during RISC assembly. 12:944-949. doi: 10.1038/embor.2011.128

29. Winter J, Diederichs S (2011) MicroRNA biogenesis and cancer. Methods Mol Biol 676:3-22. doi:10.1007/978-1-60761-863-8_1

30. Stoorvogel W (2012) Functional transfer of microRNA by exosomes. Blood 119:646-648. doi:10.1182/blood-2011-11-389478

31. Chen X, Liang H, Zhang J et al (2012) Horizontal transfer of microRNAs: molecular mechanisms and clinical applications. Protein Cell 3:28-37. doi:10.1007/s13238-012-2003-z

32. Lu J, Getz G, Miska EA, et al. (2005) MicroRNA expression profiles classify human cancers. 435:834-838. doi:10.1038/ nature 03702

33. Calin GA, Ferracin M, Cimmino A et al (2005) A MicroRNA signature associated with prognosis and progression in chronic lymphocytic leukemia. N Engl J Med 353:1793-1801. doi:10. 1056/NEJMoa050995

34. Takamizawa J (2004) Reduced expression of the let-7 MicroRNAs in human lung cancers in association with shortened postoperative survival. Cancer Res 64:3753-3756. doi:10.1158/0008-5472.CAN-04-0637

35. Yanaihara N, Caplen N, Bowman E et al (2006) Unique microRNA molecular profiles in lung cancer diagnosis and prognosis. Cancer Cell 9:189-198. doi:10.1016/j.ccr.2006.01.025

36. Kim T-M, Huang W, Park R et al (2011) A developmental taxonomy of glioblastoma defined and maintained by microRNAs. Cancer Res 71:3387-3399. doi:10.1158/0008-5472.CAN-10-4117

37. Volinia S, Calin GA, Liu C-G et al (2006) A microRNA expression signature of human solid tumors defines cancer gene targets. Proc 
Natl Acad Sci U S A 103:2257-2261. doi:10.1073/pnas. 0510565103

38. Møller HG, Rasmussen AP, Andersen HH et al (2013) A systematic review of microRNA in glioblastoma multiforme: micromodulators in the mesenchymal mode of migration and invasion. Mol Neurobiol 47:131-144. doi:10.1007/s12035-012-8349-7

39. Malzkorn B, Wolter M, Liesenberg F et al (2010) Identification and functional characterization of microRNAs involved in the malignant progression of gliomas. Brain Pathol 20:539-550. doi:10.1111/j. 1750-3639.2009.00328.x

40. Lages E, Guttin A, El Atifi M et al (2011) MicroRNA and target protein patterns reveal physiopathological features of glioma subtypes. PLoS ONE 6:e20600. doi:10.1371/journal.pone.0020600

41. Ciafre SA, Galardi S, Mangiola A et al (2005) Extensive modulation of a set of microRNAs in primary glioblastoma. Biochem Biophys Res Commun 334:1351-1358. doi:10.1016/j.bbrc.2005.07.030

42. Lavon I, Zrihan D, Granit A et al (2010) Gliomas display a microRNA expression profile reminiscent of neural precursor cells. Neuro-Oncol 12:422-433. doi:10.1093/neuonc/nop061

43. Li Y, Zhao S, Zhen Y et al (2011) A miR-21 inhibitor enhances apoptosis and reduces $\mathrm{G}(2)-\mathrm{M}$ accumulation induced by ionizing radiation in human glioblastoma U251 cells. Brain Tumor Pathol 28:209-214. doi:10.1007/s10014-011-0037-1

44. Gabriely G, Würdinger T, Kesari S et al (2008) MicroRNA 21 promotes glioma invasion by targeting matrix metalloproteinase regulators. Mol Cell Biol 28:5369-5380. doi:10.1128/MCB.00479-08

45. Dong H, Luo L, Hong S et al (2010) Integrated analysis of mutations, miRNA and mRNA expression in glioblastoma. BMC Syst Biol 4:163. doi:10.1186/1752-0509-4-163

46. Chan JA, Krichevsky AM, Kosik KS (2005) MicroRNA-21 is an antiapoptotic factor in human glioblastoma cells. Cancer Res 65: 6029-6033. doi:10.1158/0008-5472.CAN-05-0137

47. Schramedei K, Mörbt N, Pfeifer G et al (2011) MicroRNA-21 targets tumor suppressor genes ANP32A and SMARCA4. Oncogene 30:2975-2985. doi:10.1038/onc.2011.15

48. Zhou X, Ren Y, Moore L et al (2010) Downregulation of miR-21 inhibits EGFR pathway and suppresses the growth of human glioblastoma cells independent of PTEN status. Lab Invest 90:144-155. doi:10.1038/labinvest.2009.126

49. Zhou X, Zhang J, Jia Q et al (2010) Reduction of miR-21 induces glioma cell apoptosis via activating caspase 9 and 3. Oncol Rep 24: 195-201

50. Kwak H-J, Kim Y-J, Chun K-R et al (2011) Downregulation of Spry 2 by miR-2 1 triggers malignancy in human gliomas. Oncogene 30:2433-2442. doi:10.1038/onc.2010.620

51. Zhi F, Chen X, Wang S et al (2010) The use of hsa-miR-21, hsamiR-181b and hsa-miR-106a as prognostic indicators of astrocytoma. Eur J Cancer 46:1640-1649. doi:10.1016/j.ejca.2010.02.003

52. Shi L, Chen J, Yang J et al (2010) MiR-21 protected human glioblastoma U87MG cells from chemotherapeutic drug temozolomide induced apoptosis by decreasing Bax/Bcl-2 ratio and caspase3 activity. Brain Res 1352:255-264. doi:10.1016/j.brainres.2010. 07.009

53. Corsten MF, Miranda R, Kasmieh R et al (2007) MicroRNA-21 knockdown disrupts glioma growth in vivo and displays synergistic cytotoxicity with neural precursor cell delivered S-TRAIL in human gliomas. Cancer Res 67:8994-9000. doi:10.1158/0008-5472.CAN07-1045

54. Ren Y, Zhou X, Mei M et al (2010) MicroRNA-21 inhibitor sensitizes human glioblastoma cells U251 (PTEN-mutant) and LN229 (PTEN-wild type) to taxol. BMC Cancer 10:27. doi:10. 1186/1471-2407-10-27

55. Ren Y, Kang C-S, Yuan X-B et al (2010) Co-delivery of as-miR-21 and 5-FU by poly(amidoamine) dendrimer attenuates human glioma cell growth in vitro. J Biomater Sci Polym Ed 21:303-314. doi:10. $1163 / 156856209$ X415828
56. Li D, Chen P, Li X-Y et al (2011) Grade-specific expression profiles of miRNAs/mRNAs and docking study in human grade I-III astrocytomas. OMICS 15:673-682. doi:10.1089/omi.2011.0064

57. Chaudhry MA, Sachdeva H, Omaruddin RA (2010) Radiationinduced micro-RNA modulation in glioblastoma cells differing in DNA-repair pathways. DNA Cell Biol 29:553-561. doi:10.1089/ dna.2009.0978

58. Li Y, Li W, Yang Y et al (2009) MicroRNA-21 targets LRRFIP1 and contributes to VM-26 resistance in glioblastoma multiforme. Brain Res 1286:13-18. doi:10.1016/j.brainres.2009.06.053

59. Gaur AB, Holbeck SL, Colburn NH, Israel MA (2011) Downregulation of Pdcd4 by mir-21 facilitates glioblastoma proliferation in vivo. Neuro-Oncol 13:580-590. doi:10.1093/neuonc/ nor033

60. Silber J, Lim DA, Petritsch C et al (2008) miR-124 and miR-137 inhibit proliferation of glioblastoma multiforme cells and induce differentiation of brain tumor stem cells. BMC Med 6:14. doi:10. 1186/1741-7015-6-14

61. Sasayama T, Nishihara M, Kondoh T et al (2009) MicroRNA-10b is overexpressed in malignant glioma and associated with tumor invasive factors, uPAR and RhoC. Int J Cancer 125:1407-1413. doi:10. 1002/ijc. 24522

62. Zhang C, Han L, Zhang A et al (2010) Global changes of mRNA expression reveals an increased activity of the interferon-induced signal transducer and activator of transcription (STAT) pathway by repression of miR-221/222 in glioblastoma U251 cells. Int J Oncol 36:1503-1512

63. Conti A, Aguennouz M, La Torre D et al (2009) miR-21 and 221 upregulation and miR-181b downregulation in human grade II-IV astrocytic tumors. J Neurooncol 93:325-332. doi:10.1007/s11060009-9797-4

64. Huse JT, Brennan C, Hambardzumyan D et al (2009) The PTENregulating microRNA miR-26a is amplified in high-grade glioma and facilitates gliomagenesis in vivo. Genes Dev 23:1327-1337. doi:10.1101/gad.1777409

65. Guan Y, Mizoguchi M, Yoshimoto K et al (2010) MiRNA-196 is upregulated in glioblastoma but not in anaplastic astrocytoma and has prognostic significance. Clin Cancer Res 16:4289-4297. doi:10. 1158/1078-0432.CCR-10-0207

66. Rao SAM, Santosh V, Somasundaram K (2010) Genome-wide expression profiling identifies deregulated miRNAs in malignant astrocytoma. Mod Pathol 23:1404-1417. doi:10.1038/modpathol. 2010.135

67. Wuchty S, Arjona D, Li A et al (2011) Prediction of associations between microRNAs and gene expression in glioma biology. PLoS ONE 6:e14681. doi:10.1371/journal.pone.0014681

68. Papagiannakopoulos T, Shapiro A, Kosik KS (2008) MicroRNA-21 targets a network of key tumor-suppressive pathways in glioblastoma cells. Cancer Res 68:8164-8172. doi:10.1158/0008-5472.CAN08-1305

69. Quintavalle C, Donnarumma E, Iaboni M et al (2013) Effect of miR-21 and miR-30b/c on TRAIL-induced apoptosis in glioma cells. Oncogene 32:4001-4008. doi:10.1038/onc.2012.410

70. Chao T-F, Xiong H-H, Liu W et al (2013) MiR-21 mediates the radiation resistance of glioblastoma cells by regulating PDCD4 and hMSH2. J Huazhong Univ Sci Technol Med Sci 33:525-529. doi: 10.1007/s11596-013-1153-4

71. Delfino KR, Serão NVL, Southey BR, Rodriguez-Zas SL (2011) Therapy-, gender- and race-specific microRNA markers, target genes and networks related to glioblastoma recurrence and survival. Cancer Genomics Proteomics 8:173-183

72. Quant EC, Wen PY (2010) Response assessment in neuro-oncology. Curr Oncol Rep 13:50-56. doi:10.1007/s11912-010-0143-y

73. Reardon DA, Galanis E, DeGroot JF et al (2011) Clinical trial end points for high-grade glioma: the evolving landscape. Neuro-Oncol 13:353-361. doi:10.1093/neuonc/noq203 
74. Chinot OL, Macdonald DR, Abrey LE et al (2013) Response assessment criteria for glioblastoma: practical adaptation and implementation in clinical trials of antiangiogenic therapy. Curr Neurol Neurosci Rep 13:347. doi:10.1007/s11910-013-0347-2

75. Levin VA, Crafts DC, Norman DM et al (1977) Criteria for evaluating patients undergoing chemotherapy for malignant brain tumors. J Neurosurg 47:329-335. doi:10.3171/jns.1977.47.3.0329

76. Macdonald DR, Cascino TL, Schold SC, Cairncross JG (1990) Response criteria for phase II studies of supratentorial malignant glioma. J Clin Oncol 8:1277-1280

77. Brandsma D, van den Bent MJ (2009) Pseudoprogression and pseudoresponse in the treatment of gliomas. Curr Opin Neurol 22: 633-638. doi:10.1097/WCO.0b013e328332363e

78. Friedman HS, Prados MD, Wen PY et al (2009) Bevacizumab alone and in combination with irinotecan in recurrent glioblastoma. J Clin Oncol 27:4733-4740. doi:10.1200/JCO.2008.19.8721

79. Hygino da Cruz LC, Rodriguez I, Domingues RC et al (2011) Pseudoprogression and pseudoresponse: imaging challenges in the assessment of posttreatment glioma. Am J Neuroradiol 32:19781985. doi:10.3174/ajnr.A2397

80. Chinot OL, Motte Rouge T, Moore N et al (2011) AVAglio: phase 3 trial of bevacizumab plus temozolomide and radiotherapy in newly diagnosed glioblastoma multiforme. Adv Ther 28:334-340. doi:10. 1007/s12325-011-0007-3

81. Tao T, Wang Y, Luo H et al (2013) Involvement of FOS-mediated miR-181b/miR-21 signalling in the progression of malignant gliomas. Eur J Cancer 49:3055-3063. doi:10.1016/j.ejca.2013.05.010

82. Ma R, Yan W, Zhang G et al (2012) Upregulation of miR-196b confers a poor prognosis in glioblastoma patients via inducing a proliferative phenotype. PLoS ONE 7:e38096. doi:10.1371/journal.pone.0038096

83. Wu Z, Sun L, Wang H et al (2012) MiR-328 expression is decreased in high-grade gliomas and is associated with worse survival in primary glioblastoma. PLoS ONE 7:e47270. doi:10.1371/journal. pone. 0047270

84. Li Y, Xu J, Chen H et al (2013) Comprehensive analysis of the functional microRNA-mRNA regulatory network identifies miRNA signatures associated with glioma malignant progression. Nucleic Acids Res 41:e203. doi:10.1093/nar/gkt1054

85. Gabriely G, Yi M, Narayan RS et al (2011) Human glioma growth is controlled by microRNA-10b. Cancer Res 71:3563-3572. doi:10. 1158/0008-5472.CAN-10-3568

86. Guessous F, Alvarado-Velez M, Marcinkiewicz L et al (2013) Oncogenic effects of miR-10b in glioblastoma stem cells. J Neurooncol 112:153-163. doi:10.1007/s11060-013-1047-0

87. Srinivasan S, Patric IRP, Somasundaram K (2011) A ten-microRNA expression signature predicts survival in glioblastoma. PLoS ONE 6:e17438. doi:10.1371/journal.pone.0017438

88. Zinn PO, Sathyan P, Mahajan B et al (2012) A novel volume-ageKPS (VAK) glioblastoma classification identifies a prognostic cognate microRNA-gene signature. PLoS ONE 7:e41522. doi:10.1371/ journal.pone.0041522

89. Bozdag S, Li A, Riddick G et al (2013) Age-specific signatures of glioblastoma at the genomic, genetic, and epigenetic levels. PLoS ONE 8:e62982. doi:10.1371/journal.pone.0062982

90. Zhang W, Zhang J, Hoadley K et al (2012) miR-181d: a predictive glioblastoma biomarker that downregulates MGMT expression. Neuro-Oncol 14:712-719. doi:10.1093/neuonc/nos089

91. Zhang W, Zhang J, Yan W et al (2013) Whole-genome microRNA expression profiling identifies a 5-microRNA signature as a prognostic biomarker in Chinese patients with primary glioblastoma multiforme. Cancer 119:814-824. doi:10.1002/cncr.27826

92. Quintavalle C, Mangani D, Roscigno G et al (2013) MiR-221/222 target the DNA methyltransferase MGMT in glioma cells. PLoS ONE 8:e74466. doi:10.1371/journal.pone.0074466

93. de Biase D, Visani M, Morandi L et al (2012) miRNAs expression analysis in paired fresh/frozen and dissected formalin fixed and paraffin embedded glioblastoma using real-time pCR. PLoS ONE 7:e35596. doi:10.1371/journal.pone.0035596

94. Niyazi M, Zehentmayr F, Niemöller OM et al (2011) MiRNA expression patterns predict survival in glioblastoma. Radiat Oncol 6:153. doi:10.1186/1748-717X-6-153

95. Ilhan-Mutlu A, Wöhrer A, Berghoff AS et al (2013) Comparison of microRNA expression levels between initial and recurrent glioblastoma specimens. J Neurooncol 112:347-354. doi:10.1007/s11060013-1078-6

96. Zhang C, Zhang J, Hao J et al (2012) High level of miR-221/222 confers increased cell invasion and poor prognosis in glioma. $\mathrm{J}$ Transl Med 10:119. doi:10.1186/1479-5876-10-119

97. Dews M, Fox JL, Hultine S et al (2010) The myc-miR-17 92 axis blunts TGF \{beta\} signaling and production of multiple TGF \{beta $\}$ dependent antiangiogenic factors. Cancer Res 70:8233-8246. doi: 10.1158/0008-5472.CAN-10-2412

98. Yang G, Zhang R, Chen X et al (2011) MiR-106a inhibits glioma cell growth by targeting E2F1 independent of p53 status. J Mol Med 89:1037-1050. doi:10.1007/s00109-011-0775-x

99. Shi Z-M, Yan Z et al (2012) MiR-128 inhibits tumor growth and angiogenesis by targeting p70S6K1. PLoS ONE 7:10. doi:10.1371/ journal.pone.0032709.g007

100. Vo DT, Qiao M, Smith AD et al (2011) The oncogenic RNAbinding protein Musashil is regulated by tumor suppressor miRNAs. RNA Biol 8:817-828. doi:10.4161/rna.8.5.16041

101. Cui JG, Zhao Y, Sethi P et al (2010) Micro-RNA-128 (miRNA-128) down-regulation in glioblastoma targets ARP5 (ANGPTL6), Bmi-1 and E2F-3a, key regulators of brain cell proliferation. J Neurooncol 98:297-304. doi:10.1007/s11060-009-0077-0

102. Zhang Y, Chao T, Li R et al (2009) MicroRNA-128 inhibits glioma cells proliferation by targeting transcription factor E2F3a. J Mol Med 87:43-51. doi:10.1007/s00109-008-0403-6

103. Godlewski J, Nowicki MO, Bronisz A et al (2008) Targeting of the Bmi-1 oncogene/stem cell renewal factor by microRNA-128 inhibits glioma proliferation and self-renewal. Cancer Res 68:91259130. doi:10.1158/0008-5472.CAN-08-2629

104. Wang X-F, Shi Z-M, Wang X-R et al (2012) MiR-181d acts as a tumor suppressor in glioma by targeting K-ras and Bcl-2. J Cancer Res Clin Oncol 138:573-584. doi:10.1007/s00432-011-1114-x

105. Kreth S, Limbeck E, Hinske LC et al (2013) In human glioblastomas transcript elongation by alternative polyadenylation and miRNA targeting is a potent mechanism of MGMT silencing. Acta Neuropathol 125:671-681. doi:10.1007/s00401-013-1081-1

106. Guessous F, Zhang Y, Kofman A et al (2010) microRNA-34a is tumor suppressive in brain tumors and glioma stem cells. Cell Cycle 9:1031-1036

107. Yin D, Ogawa S, Kawamata N et al (2012) miR-34a functions as a tumor suppressor modulating EGFR in glioblastoma multiforme. Oncogene 32:1155-1163. doi:10.1038/onc.2012.132

108. Xia H, Qi Y, Ng SS et al (2009) microRNA-146b inhibits glioma cell migration and invasion by targeting MMPs. Brain Res 1269: 158-165. doi:10.1016/j.brainres.2009.02.037

109. Katakowski M, Zheng X, Jiang F et al (2010) MiR-146b-5p suppresses EGFR expression and reduces in vitro migration and invasion of glioma. Cancer Invest 28:1024-1030. doi:10.3109/ 07357907.2010.512596

110. Zhang C-Z, Zhang J-X, Zhang A-L et al (2010) MiR-221 and miR222 target PUMA to induce cell survival in glioblastoma. Mol Cancer 9:229. doi:10.1186/1476-4598-9-229

111. Medina R, Zaidi SK, Liu C-G et al (2008) MicroRNAs 221 and 222 bypass quiescence and compromise cell survival. Cancer Res 68: 2773-2780. doi:10.1158/0008-5472.CAN-07-6754

112. Wang S, Lu S, Geng S et al (2013) Expression and clinical significance of microRNA-326 in human glioma miR-326 expression in glioma. Med Oncol 30:373. doi:10.1007/ s12032-012-0373-y 
113. Lu X, Zhao P, Zhang C et al (2009) Analysis of miR-221 and p27 expression in human gliomas. Mol Med Rep 2:651-656. doi:10. $3892 / \mathrm{mmr} 00000152$

114. Hao J, Zhang C, Zhang A et al (2012) miR-221/222 is the regulator of Cx43 expression in human glioblastoma cells. Oncol Rep 27: 1504-1510. doi:10.3892/or.2012.1652

115. Hui W, Yuntao L, Lun L et al (2013) MicroRNA-195 inhibits the proliferation of human glioma cells by directly targeting cyclin D1 and cyclin E1. PLoS ONE 8:e54932. doi:10.1371/journal.pone.0054932

116. Zhang Q-Q, Xu H, Huang M-B et al (2012) MicroRNA-195 plays a tumor-suppressor role in human glioblastoma cells by targeting signaling pathways involved in cellular proliferation and invasion. Neuro-Oncol 14:278-287. doi:10.1093/neuonc/nor216

117. Yang Y, Wu J, Guan $\mathrm{H}$ et al (2012) MiR-136 promotes apoptosis of glioma cells by targeting AEG-1 and Bcl-2. FEBS Lett 586:36083612. doi:10.1016/j.febslet.2012.08.003

118. Zhong J, Paul A, Kellie SJ, O'Neill GM (2010) Mesenchymal migration as a therapeutic target in glioblastoma. J Oncol 2010: 430142. doi: $10.1155 / 2010 / 430142$

119. Tivnan A, McDonald KL (2013) Current progress for the use of miRNAs in glioblastoma treatment. Mol Neurobiol. doi:10.1007/ s12035-013-8464-0

120. Griveau A, Bejaud J, Anthiya S et al (2013) Silencing of miR-21 by locked nucleic acid-lipid nanocapsule complexes sensitize human glioblastoma cells to radiation-induced cell death. Int J Pharm 454: 765-774. doi:10.1016/j.ijpharm.2013.05.049

121. Katakowski M, Buller B, Zheng X et al (2013) Exosomes from marrow stromal cells expressing miR-146b inhibit glioma growth. Cancer Lett 335:201-204. doi:10.1016/j.canlet.2013.02.019

122. Wang W, Dai LX, Zhang S et al (2013) Regulation of epidermal growth factor receptor signaling by plasmid-based microRNA-7 inhibits human malignant gliomas growth and metastasis in vivo. Neoplasma 60:274-283. doi:10.4149/neo_2013_036

123. Liu X, Li G, Su Z et al (2013) Poly(amido amine) is an ideal carrier of miR-7 for enhancing gene silencing effects on the EGFR pathway in U251 glioma cells. Oncol Rep 29:1387-1394. doi:10.3892/or. 2013.2283

124. Lee Y, El Andaloussi S, Wood MJA (2012) Exosomes and microvesicles: extracellular vesicles for genetic information transfer and gene therapy. Hum Mol Genet. doi:10.1093/hmg/dds317

125. El Andaloussi S, Mäger I, Breakefield XO, Wood MJA (2013) Extracellular vesicles: biology and emerging therapeutic opportunities. Nat Rev Drug Discov. doi:10.1038/nrd3978

126. Vlassov AV, Magdaleno S, Setterquist R, Conrad R (2012) Exosomes: current knowledge of their composition, biological functions, and diagnostic and therapeutic potentials. Biochim Biophys Acta 1820:940-948. doi:10.1016/j.bbagen.2012.03.017

127. Valadi H, Ekström K, Bossios A et al (2007) Exosome-mediated transfer of mRNAs and microRNAs is a novel mechanism of genetic exchange between cells. Nat Cell Biol 9:654-659. doi:10. $1038 /$ ncb1596

128. Katakowski M, Buller B, Wang X et al (2010) Functional microRNA is transferred between glioma cells. Cancer Res 70: 8259-8263. doi:10.1158/0008-5472.CAN-10-0604

129. Alvarez-Erviti L, Seow Y, Yin H et al (2011) Delivery of siRNA to the mouse brain by systemic injection of targeted exosomes. Nat Biotechnol 29:341-345. doi:10.1038/nbt.1807

130. Ohno S-I, Takanashi M, Sudo K et al (2012) Systemically injected exosomes targeted to EGFR deliver antitumor MicroRNA to breast cancer cells. Mol Ther. doi:10.1038/mt.2012.180

131. Munoz JL, Bliss SA, Greco SJ et al (2013) Delivery of functional anti-miR-9 by mesenchymal stem cell-derived exosomes to glioblastoma multiforme cells conferred chemosensitivity. Mol Ther Nucleic Acids 2:e126. doi:10.1038/mtna.2013.60

132. Dai D-W, Lu Q, Wang L-X et al (2013) Decreased miR-106a inhibits glioma cell glucose uptake and proliferation by targeting
SLC2A3 in GBM. BMC Cancer 13:478. doi:10.1186/1471-2407$13-478$

133. Genovese G, Ergun A, Shukla SA et al (2012) MicroRNA regulatory network inference identifies miR-34a as a novel regulator of TGF- signaling in glioblastoma. Cancer Discov 2:736-749. doi:10. 1158/2159-8290.CD-12-0111

134. Haapa-Paananen S, Chen P, Hellström K et al (2013) Functional profiling of precursor microRNAs identifies MicroRNAs essential for glioma proliferation. PLoS ONE 8:e60930. doi:10.1371/journal. pone.0060930

135. Hua Y, Larsen N, Kalyana-Sundaram S et al (2013) miRConnect 2.0: identification of oncogenic, antagonistic miRNA families in three human cancers. BMC Genomics 14:179. doi:10.1186/14712164-14-179

136. Lee HK, Bier A, Cazacu S et al (2013) MicroRNA-145 is downregulated in glial tumors and regulates glioma cell migration by targeting connective tissue growth factor. PLoS ONE 8:e54652. doi: 10.1371/journal.pone.0054652

137. Qiu S, Huang D, Yin D et al (2013) Suppression of tumorigenicity by microRNA-138 through inhibition of EZH2-CDK4/6-pRb-E2F1 signal loop in glioblastoma multiforme. Biochim Biophys Acta 1832:1697-1707. doi:10.1016/j.bbadis.2013.05.015

138. Qiu S, Lin S, Hu D et al (2013) Interactions of miR-323/miR-326/ miR-329 and miR-130a/miR-155/miR-210 as prognostic indicators for clinical outcome of glioblastoma patients. J Transl Med 11:10. doi:10.1186/1479-5876-11-10

139. Suzuki HI, Mihira H, Watabe T et al (2013) Widespread inference of weighted microRNA-mediated gene regulation in cancer transcriptome analysis. Nucleic Acids Res 41:e62. doi:10.1093/nar/gks1439

140. Wang X-R, Luo H, Li H-L et al (2013) Overexpressed let-7a inhibits glioma cell malignancy by directly targeting K-ras, independently of PTEN. Neuro-Oncol 15:1491-1501. doi:10.1093/neuonc/not107

141. Xiao Y, Ping Y, Fan $\mathrm{H}$ et al (2013) Identifying dysfunctional miRNA-mRNA regulatory modules by inverse activation, cofunction, and high interconnection of target genes: a case study of glioblastoma. Neuro-Oncol 15:818-828. doi:10.1093/neuonc/ not018

142. Chang C, Shi H, Wang C et al (2012) Correlation of microRNA-375 downregulation with unfavorable clinical outcome of patients with glioma. Neurosci Lett 531:204-208. doi:10.1016/j.neulet.2012.10.021

143. Chen L, Han L, Zhang K et al (2012) VHL regulates the effects of miR-23b on glioma survival and invasion via suppression of HIF-1/ VEGF and -catenin/Tcf-4 signaling. Neuro-Oncol 14:1026-1036. doi:10.1093/neuonc/nos 122

144. Gao H, Zhao H, Xiang W (2013) Expression level of human miR34a correlates with glioma grade and prognosis. J Neurooncol 113: 221-228. doi:10.1007/s11060-013-1119-1

145. He J, Deng Y, Yang G, Xie W (2013) MicroRNA-203 downregulation is associated with unfavorable prognosis in human glioma. J Surg Oncol 108:121-125. doi:10.1002/jso.23315

146. Hermansen SK, Dahlrot RH, Nielsen BS et al (2012) MiR-21 expression in the tumor cell compartment holds unfavorable prognostic value in gliomas. J Neurooncol 111:71-81. doi:10.1007/ s11060-012-0992-3

147. Hou S-X, Ding B-J, Li H-Z et al (2013) Identification of microRNA-205 as a potential prognostic indicator for human glioma. J Clin Neurosci 20:933-937. doi:10.1016/j.jocn.2012.10.015

148. Jiang L, Mao P, Song L et al (2010) miR-182 as a prognostic marker for glioma progression and patient survival. Am J Pathol 177:29 38. doi:10.2353/ajpath.2010.090812

149. Jiang J, Sun X, Wang W et al (2012) Tumor microRNA-335 expression is associated with poor prognosis in human glioma. Med Oncol 29:3472-3477. doi:10.1007/s12032-012-0259-Z

150. Li G, Zhang Z, Tu Y et al (2013) Correlation of microrna-372 upregulation with poor prognosis in human glioma. Diagn Pathol 8:1. doi:10.1186/1746-1596-8-1 
151. Lu S, Wang S, Geng S et al (2012) Upregulation of microRNA-224 confers a poor prognosis in glioma patients. Clin Transl Oncol 15: 569-574. doi:10.1007/s12094-012-0972-2

152. Lu S, Wang S, Geng S et al (2012) Increased expression of microRNA-17 predicts poor prognosis in human glioma. $\mathrm{J}$ Biomed Biotechnol 2012:1-6. doi:10.1155/2012/970761

153. Speranza MC, Frattini V, Pisati F et al (2012) NEDD9, a novel target of miR-145, increases the invasiveness of glioblastoma. Oncotarget 3:723-734

154. Sun B, Pu B, Chu D et al (2013) MicroRNA-650 expression in glioma is associated with prognosis of patients. J Neurooncol 115: 375-380. doi:10.1007/s11060-013-1243-y

155. Wu Z, Wang L, Li G et al (2013) Increased expression of microRNA-9 predicts an unfavorable prognosis in human glioma. Mol Cell Biochem 384:263-268. doi:10.1007/s11010-013-1805-5

156. Schraivogel D, Weinmann L, Beier D et al (2011) CAMTA1 is a novel tumour suppressor regulated by miR-9/9* in glioblastoma stem cells. EMBO J 30:4309-4322. doi:10.1038/emboj.2011.301

157. Ernst A, Campos B, Meier J et al (2010) De-repression of CTGF via the miR-17-92 cluster upon differentiation of human glioblastoma spheroid cultures. Oncogene 29:3411-3422. doi:10.1038/onc.2010. 83

158. Skalsky RL, Cullen BR (2011) Reduced expression of brainenriched microRNAs in glioblastomas permits targeted regulation of a cell death gene. PLoS ONE 6:e24248. doi:10.1371/journal. pone. 0024248

159. Tian RQ, Wang XH, Hou LJ et al (2011) MicroRNA-372 is downregulated and targets cyclin-dependent kinase 2 (CDK2) and cyclin A1 in human cervical cancer, which may contribute to tumorigenesis. J Biol Chem 286:25556-25563. doi:10.1074/jbc.M111. 221564

160. Zhang Y, Dutta A, Abounader R (2012) The role of microRNAs in glioma initiation and progression. Front Biosci 17:700-712

161. Wu N, Zhao X, Liu M et al (2011) Role of microRNA-26b in glioma development and its mediated regulation on EphA2. PLoS ONE 6:e16264. doi:10.1371/journal.pone.0016264

162. Luan S, Sun L, Huang F (2010) MicroRNA-34a: a novel tumor suppressor in p53-mutant glioma cell line U251. Arch Med Res 41: 67-74. doi:10.1016/j.arcmed.2010.02.007

163. Li Y, Guessous F, Zhang Y et al (2009) MicroRNA-34a inhibits glioblastoma growth by targeting multiple oncogenes. Cancer Res 69:7569-7576. doi:10.1158/0008-5472.CAN-09-0529

164. Silber J, Jacobsen A, Ozawa T et al (2012) miR-34a repression in proneural malignant gliomas upregulates expression of its target
PDGFRA and promotes tumorigenesis. PLoS ONE 7:e33844. doi: 10.1371/journal.pone.0033844

165. Meng W, Jiang L, Lu L et al (2012) Anti-miR-155 oligonucleotide enhances chemosensitivity of U251 cell to taxol by inducing apoptosis. Cell Biol Int. doi:10.1042/CBI20100918

166. Zhang J, Han L, Ge Y et al (2010) miR-221/222 promote malignant progression of glioma through activation of the Akt pathway. Int J Oncol 36:913-920

167. Lukiw WJ, Cui JG, Li YY, Culicchia F (2009) Up-regulation of micro-RNA-221 (miRNA-221; chr Xp11.3) and caspase-3 accompanies down-regulation of the survivin-1 homolog BIRC1 (NAIP) in glioblastoma multiforme (GBM). J Neurooncol 91:27-32. doi: 10.1007/s11060-008-9688-0

168. Quintavalle C, Garofalo M, Zanca C et al (2012) miR-221/222 overexpession in human glioblastoma increases invasiveness by targeting the protein phosphate РTP $\mu$. Oncogene 31:858-868. doi: 10.1038/onc.2011.280

169. Wang X, Han L, Zhang A et al (2011) Adenovirus-mediated shRNAs for co-repression of miR-221 and miR-222 expression and function in glioblastoma cells. Oncol Rep 25:97-105

170. D'Urso PI, D'Urso OF, Storelli C et al (2012) miR-155 is upregulated in primary and secondary glioblastoma and promotes tumour growth by inhibiting GABA receptors. Int J Oncol. doi:10. 3892/ijo.2012.1420

171. Ling N, Gu J, Lei Z et al (2013) MicroRNA-155 regulates cell proliferation and invasion by targeting FOXO3a in glioma. Oncol Rep 30:2111-2118. doi:10.3892/or.2013.2685

172. Li H, Yang BB (2012) Stress response of glioblastoma cells mediated by miR-17-5p targeting PTEN and the passenger strand miR17-3p targeting MDM2. Oncotarget 3:1653-1668

173. Wang J, Sai K, Chen F-R, Chen Z-P (2013) miR-181b modulates glioma cell sensitivity to temozolomide by targeting MEK1. Cancer Chemother Pharmacol 72:147-158. doi:10.1007/s00280-013-21803

174. Shi Z-M, Wang X-F, Qian X et al (2013) MiRNA-181b suppresses IGF-1R and functions as a tumor suppressor gene in gliomas. RNA 19:552-560. doi:10.1261/rna.035972.112

175. Han L, Yue X, Zhou X et al (2012) MicroRNA-21 expression is regulated by $\beta$-catenin/STAT3 pathway and promotes glioma cell invasion by direct targeting RECK. CNS Neurosci Ther 18:573583. doi:10.1111/j.1755-5949.2012.00344.x

176. Li W, Guo F, Wang P, et al. (2012) MiR-221/222 confers radioresistance in glioblastoma cells through activating Akt independent of PTEN status. Curr Mol Med 18(7):573-583 